NBS

PUBLICATIONS

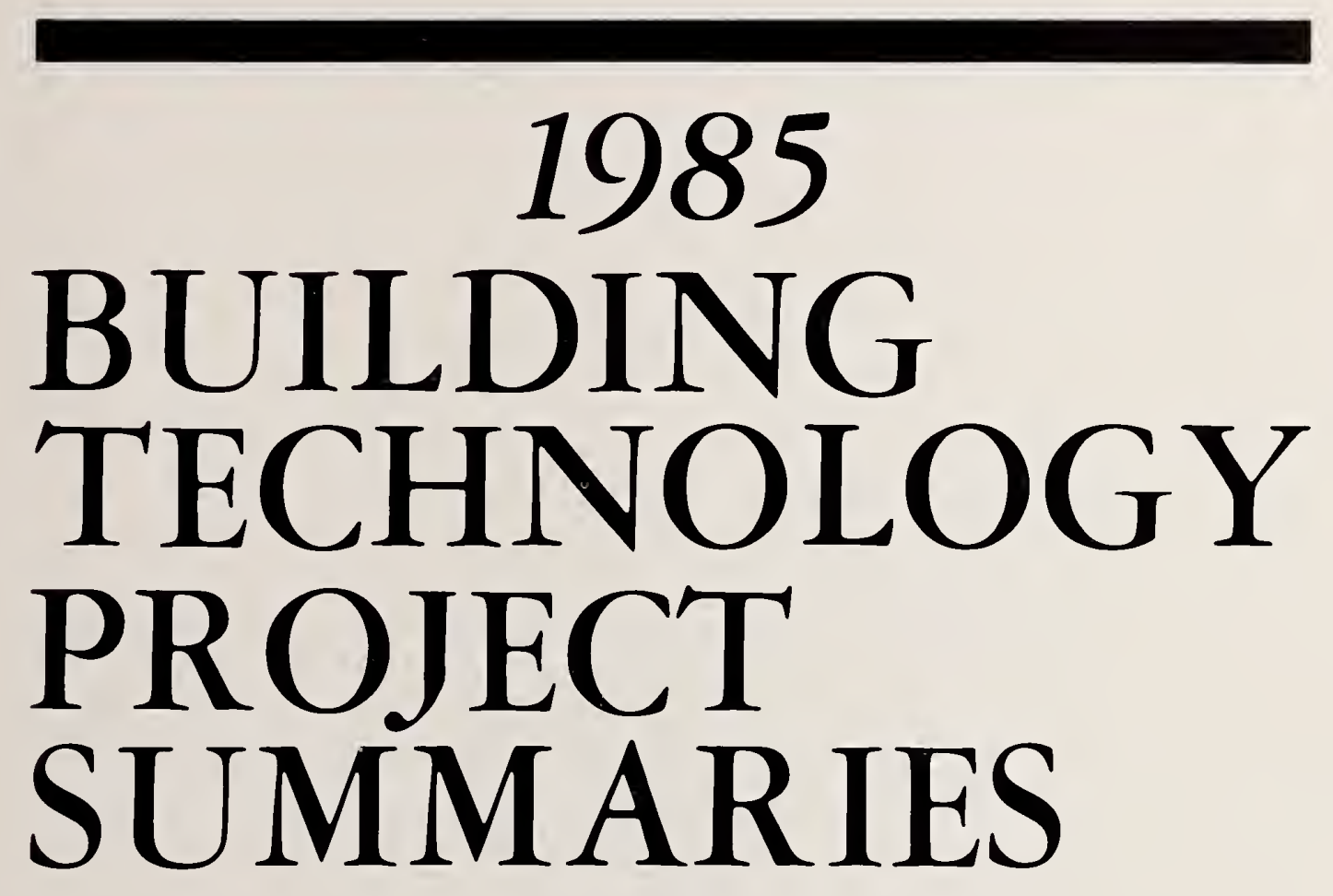

U.S. Department of Commerce National Bureau of Standards Special Publication 446-9

$A C$ 



\title{
1985 \\ BUILDING TECHNOLOGY \\ PROJECT \\ SUMMARIES
}

\section{Special Publication 446-9}

\author{
Editors \\ Noel Raufaste \\ Michael Olmert
}

Center for Building Technology

National Engineering Laboratory

National Bureau of Standards

U.S. Department of Commerce

Gaithersburg, MD 20899

\section{Issued June 1985}

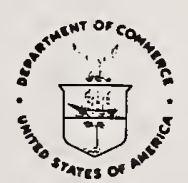

U.S. DEPARTMENT OF COMMERCE, Malcolm Baldrige, Secretary

NATIONAL BUREAU OF STANDARDS, Ernest Ambler, Director 
National Bureau of Standards Special Publication 446-9

Natl. Bur. Stand. (U.S.), Spec. Publ. 446-9, 175 pages (June 1985) CODEN: XNBSAV 


\section{FOREWORD}

The building research program of the National Bureau of Standards, the Nation's central engineering measurements laboratory, is conducted by its Center for Building Technology (CBT). CBT works cooperatively with other organizations, private and public, to improve building practices. It conducts laboratory, field, and analytical research. It develops technologies to predict, measure, and test the performance of building materials, components, systems, and practices. This knowledge is required for responsible and costeffective decisions in the building process and cannot be obtained through proprietary research and development. CBT provides technologies needed by the building community to achieve the benefits of advanced computation and automation. CBT does not promulgate building standards or regulations, but its technologies are widely used in the building industry and adopted by governmental and private organizations that have standards and codes responsibilities.

Construction is one of the Nation's largest industries. In 1984, new construction put in place amounted to $\$ 310$ billion, 8.4 percent of the Gross National Product. Over two-thirds of the Nation's fixed reproducible wealth is invested in constructed facilities that shelter and support most human activities.

CBT research provides knowledge for decisionmaking. This knowledge includes characterization of the environments in which buildings must operate (such as wind loadings), characterization and definition of the performance of buildings, components, and systems (such as the mechanisms for heat loss through a window or wall cladding element), and methods of testing for performance 
qualities that will apply equitably to a whole family of potentially competitive proprietary materials and components.

The CBT staff of 160 includes 100 professionals, of whom 30 are registered professional engineers and 50 hold doctorates. The principal disciplines are structural, geotechnical, materials, electrical, and mechanical engineering, physics, and chemistry.

Among the variety of special facilities and equipment at CBT are a largescale testing facility including a reaction buttress 45 feet high with a latent force capacity of 1.2 million pounds in conjunction with the universal testing machine of 12-million-pound capacity is capable of testing structural components 60 feet in height; a tri-directional structural testing facility with its associated computer control data acquisition and processing equipment capable of applying forces or displacements in three directions simultaneously to full-scale structural components and systems; seven environmental chambers, including a $30 \times 40 \times 50-\mathrm{ft}$ chamber, for developing thermal performance modeling techniques required for predicting human comfort and energy efficiency of buildings; a guarded hot-plate that measures insulation performance of thicknesses up to 15 inches; a calibrated hot-box to provide precise measurements of heat and moisture transfer in full-scale building wall and roof sections; a five-story plumbing research laboratory with high-speed computer data acquisition system to study the performance of water supply and drainage systems; reverberation and anechoic chambers, each 15,000 $\mathrm{ft}^{3}$, to define acoustical parameters for building materials and methods to evaluate acoustical performance; daylighting laboratories; an illumination color laboratory capable of presenting eight light sources independently; an outdoor solar-collector test-method development area, including a passive solar test house and facilities for experimental 
solar heating and cooling systems; a network of outdoor material exposure sites; materials reference laboratories include the Cement and Concrete Reference Laboratory sponsored by the American Society for Testing and Materials and the AASHTO Materials Reference Laboratory sponsored by the American Association of State Highways and Transportation Officials; and a materials research laboratory with a scanning electron microscope and other instruments for materials characterization.

This report summarizes $\mathrm{CBT}^{\prime}$ 's research for 1985 , and is arranged according to $\mathrm{CBT}^{\prime}$ 's research programs. Each summary lists the project title, its activities, point of contact in CBT, and sponsor. The reader is encouraged to review the companion document, NBS Special Publication 457, Building Technology Publications, and its supplements. Final reports on the projects described here will be listed in future issues of Building Technology Publications. 



\section{CONTENTS}

\section{Computer-Integrated Construction}

Expert System for Durable Concrete. . . . . . . . . . . . 2

Expert System for Air-Infiltration Prediction

and Control in Buildings. . . . . . . . . . . . . . . 3

Expert System for Selecting Concrete for Jet

Engine Test Facilities. . . . . . . . . . . . . . . 4

Standards Interface for Computer-Aided Design . . . . . . . 5

Construction Project Information Technologies . . . . . . . . 7

Building Data Protocols . . . . . . . . . . . . . . . . 9

Representation and Analysis of Construction Standards

and Specifications. . . . . . . . . . . . . . . 10

CBT Information Management . . . . . . . . . . . . . 12

Economic Methods for Building Standards . . . . . . . . . . 13

\section{Structural Loads and Reliability}

Dynamic Behavior of Three-Dimensional Steel Buildings . . . . . 15 Analysis of General Combinations of Loads . . . . . . . . . 16 Criteria for Structural Loads and Design . . . . . . . . . 17 Dynamic Behavior of Compliant Offshore Structures . . . . . . . 19 Punching Shear Study of Reinforced Shell. . . . . . . . . 20 Mat Foundation for Offshore Gravity Structures

in Arctic Regions .. . . . . . . . . . . . . . . . 21 Reliability of Wood Structures . . . . . . . . . . . . 22 Criteria for Design of Cladding Subjected to Wind Loads . . . . 23 Behavior of Glass Cladding Subjected to Wind Loads. . . . . . . 24 Probabilistic Risk Assessments of Tornado Missle Damage . . . . 25 CBT Wind Tunne1 . . . . . . . . . . . . . . . . . 26 Structures/Mechanical Design Criteria for Low-Impact

Resistant Structures (LIRS) . . . . . . . . . . . . 27 Reliability-Based Design of Containments and Category I

Structures . . . . . . . . . . . . . . . . . 28

Structural Condition Assessment Standards . . . . . . . . . 30 Pulse Echo for Flaw Detection in Concrete . . . . . . . . . 31 NDT Methods for Concrete . . . . . . . . . . . . 32

\section{Geotechnical Engineering}

Standards for Foundations and Excavations . . . . . . . . 35 Soil Test Probe . . . . . . . . . . . . . . . . . 36 Evaluation and Expansion of Liquefaction Data Base. . . . . . 37 


\section{CONTENTS (Continued)}

\section{Earthquake Engineering}

Inelastic Performance of Reinforced Concrete Columns . . . . . 39

Inelastic Performance of Steel-Braced Frame Connections . . . . 40 Cyclic Strain Approach to Determining the Liquefaction

Potential of Level Sandy Sites . . . . . . . . . . . 4 41

Cyclic Loading of Masonry Building Components . . . . . . . . 42

Seismic Safety in Construction . . . . . . . . . . . . 43

Technical Assessment of Earthquake Resistance . . . . . . . 45

\section{Thermal Analysis and Measurements}

Evaluation of Thermal Anomalies . . . . . . . . . 4 47

Heat Losses Through Thermal Bridges . . . . . . . . . . . 48

Air Infiltration and Ventilation in Large Buildings . . . . . 49

Thermal Modeling of Buildings . . . . . . . . . . . . 50

Evaluation of an Envelope Thermal Testing Unit. . . . . . . . 51

Measurement and Modeling of Fenestration Optics . . . . . . . 52

Glazing Temperature Measurement . . . . . . . . . . . 53

Therma1 Performance of Fenestration Systems . . . . . . . . . 54

Thermal Mass -- Effect on Residential Cooling

and Heating Loads . . . . . . . . . . . . . . 56

Field Measurements of Wall Thermal Mass . . . . . . . . . . 58

Transient Heat Transfer Characteristics for Walls . . . . . . . 59

Heat Transfer Coefficients for Insulated Walls . . . . . . . 61

Experimental Heat Transfer Functions . . . . . . . . . . 62

Guarded Hot Plate Limit Assessment . . . . . . . . . . . 63

Therma1 Resistance Calibration Standard . . . . . . . . . . 65

Validation Guide for Energy Conservation Investment Program • . 66

Residential Interactive Testing Plan . . . . . . . . . . 67

Indoor Air-Pollution Concentration Mode1 . . . . . . . . 68

Pressed Wood Model Evaluation . . . . . . . . . . . 70

Specification for High-Technology Buildings . . . . . . . . 71

Underground Heat Distribution Systems . . . . . . . . . . 72

\section{Acoustics}

Building Acoustics Technology . . . . . . . . . . 75 Noise Isolation of Buildings Exposed to Aircraft Noise. . • . 77 Aircraft Noise Isolation: Residential Buildings. . . . . . . 79

\section{Lighting Research}

Daylighting Studies . . . . . . . . . . . . . . . 82

CEL-1 Lighting Program . . . . . . . . . . . . . . 83

Interaction -- Lighting and HVAC Systems. . . . . . . . . . 84

Development of Illumination Model . . . . . . . . . . . 85

Effect of Chromatic Adoption: Color Rendering and

Color Appearance 


\section{CONTENTS (Continued)}

Lighting Geometry and Contrast Measurement . . . . . . . 88

Color Calibrator for FAA Weather Radar System . . . . . . . 9 90 Safety Colors and Signs in Workplaces . . . . . . . . . . . . 91 Discriminability Features of Secure Documents . . . . . . . . 93 Design Criteria Impacts of office Information Systems . . . . . 94

\section{Building Controls}

Systems and Controls Laboratory . . . . . . . . . . . 96

Electronic Bulletin Board . . . . . . . . . . . . . . . 97

Energy Monitoring and Control System (EMCS) Algorithms •. •. 98

Controls Dynamic Modeling . . . . . . . . . . . . . . 99

Energy Analysis of Control Strategies ............. 100

\section{Non-Azeotropic Refrigerant Mixtures Research}

Refrigerant Mixture Measurements in Two-Phase Flow . . . . . .102

Performance of Non-Azeotropic Binary Refrigerants in

Residential Heat Pumps . . . . . . . . . . . . . .104

Modeling the Performance of Non-Azeotropic Refrigerants

in Heat Pumps . . . . . . . . . . . . . . 105

\section{Test Procedures for Energy Appliances}

Furnace, Boiler, and Household Appliance Test Procedures • • . 107 Household Appliance Data Update . . . . . . . . . . . 108 Water Heater Test Procedures .................109

\section{Solar Equipment}

Control Strategies to Improve Solar Systems Performance • • . .111

Test Methods and Evaluation Procedures for Controllers

Used in Active Solar Systems . . . . . . . . . . . . 112

Second-Law Analysis of Solar Water Heating Systems . . . . .113

Thermal Performance of Passive Solar Aperatures and

Storage Components . . . . . . . . . . . . . . 114

Thermal Performance of Experimental Passive Solar Systems . . . 116

Experimental Passive Solar Systems . . . . . . . . . . 117

Radiative Heat-Transfer Modeling . . . . . . . . . . 118

Inorganic Compounds for Passive Solar Energy Storage -

Solid-State Dehydration . . . . . . . . . . . . 120

Inorganic Compounds for Passive Solar Energy Storage --

High Specific Heat Materials. . . . . . . . . . . .121

Technical Problem Assessment . . . . . . . . . . . . 122

Technical Committee Assistance . . . . . . . . . . . . 123

Consulting and Advisory Services: Active Solar Heating

and Cooling . . . . . . . . . . . . . . . . 124

International Energy Agency Solar Program Support . . . . . . 125 


\section{CONTENTS (Continued)}

\section{Plumbing Research}

Hydraulic Load Limits in Drains . . . . . . . . . . . . . 128

Load Modeling For Multistory Drainage Systems . . . . . . . .129

Residence Times In Flow Separation - Water Mains . . . . . . 130

\section{Quality of Building Materials}

Application of Life-Test Analysis Concepts to Building Materials . . . . . . . . . . . . . . . . 132

Environmental Degradation of Polymeric Cover Materials for Solar Collectors . . . . . . . . . . . . . .134

Dependence of Mechanical Properties on Microstructural

Changes in Cover Plate Materials. . . . . . . . . . . .135

Development of Tests for Predicting Adhesive-Bond

Durability ........................136

Nondestructive Early Detection of Corrosion and Delaminations

Under Protective Coatings Using the Thermal Wave Method . . . .138

Assessment of Nondestructive Evaluation Methods Applicable

to Construction . . . . . . . . . . . . . . 140

Organic Coatings. . . . . . . . . . . . . . . . . 141

Improved Characterization of Coating System Performance . . . . 143

Coating Maintenance of Factory Coated Metal

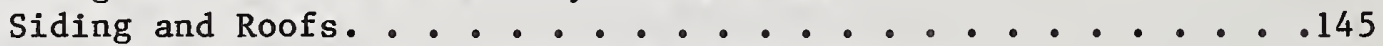

Degradation of Organic Protective Coatings. . . . . . . . . 146

Revision of Tri-Service Coatings Manual . . . . . . . . . 147

Tri-Services Technical and Scientific Support . . . . . . . . 148

AASHTO Materials Reference Laboratory . . . . . . . . . . . 149

\section{Performance of Roofing Systems}

Probabilistic Study of Single-Ply Membranes . . . . . . . . 151 Performance Criteria For Bituminous Membrane Roofing. . . . . .153 Quality Assurance of Roof Systems . . . . . . . . . . . 154

\section{Predicting the Performance and Service-Life of Concretes}

Identifying the Degradation Mechanisms of Concrete . . . . . 156 Measurement of the Strength of the Bond Between 0ld and New Concrete .. . . . . . . . . . . . . . . 158 Performance Requirements, Tests, and Criteria for Materials Used to Repair Portland Cement Concrete . . . . . .160 Alkali-Silica Reaction in Concrete. . . . . . . . . . . 162 Cement and Concrete Reference Laboratory (CCRL). . . . . . . .163 Cement Hydration Competence Project . . . . . . . . . . . . .164 


\section{COMPUTER-INTEGRATED CONSTRUCTION}




\section{EXPERT SYSTEM FOR DURABLE CONCRETE}

James R. Clifton

(301) 921-3458

Building Materials Division

Sponsor: National Bureau of Standards

Because of the potential importance of expert systems in selecting durable building materials, knowledge of generic aspects of their development and use is needed. Concrete was selected as the subject of a prototype expert system for building materials selection for the following reasons. Concrete is the most widely-used man-made construction material in the world. In the United States alone over 700 million tons of concrete are placed each year. Although a large knowledge base for selecting constituents for making durable concrete is available, the knowledge is not easily available to all who need it. The purpose of this project is to develop a prototype expert system that systematically provides recommendations in the selection of constituents for concrete subjected to a broad range of service conditions.

In developing the expert system, the effects of the constituents of concrete on its major deterioration processes will be identified. Deterioration processes which are being considered include freeze-thaw, sulfate attack, corrosion of reinforcement, and expansive reactions between cement and aggregates. Then recommendations by experts on selecting constituents for concrete subjected to such deterioration processes will be used as the basis for production rules. This work will demonstrate the value of developing and using expert systems, and provides an effective means for assessing durable concrete. The expert system also will be useful to identify gaps in knowledge and guide future research on concrete durability. 


\section{EXPERT SYSTEM FOR AIR-INFILTRATION PREDICTION AND CONTROL IN BUILDINGS}

Andrew Persily

(301) 921-2330

Building Physics Division

Sponsor: National Bureau of Standards

This research will couple expert system techniques with more

traditional computational techniques to develop an expert system capable of predicting building air-infiltration rates and diagnosing potential air-leakage problems. The knowledge base of the expert system will include existing engineering knowledge concerning air infiltration as well as heuristic knowledge based on field experience with air-leakage problems. CBT's Thermal Analysis Research Program (TARP) will be used to predict air-infiltration rates. CBT is developing a system to determine how a particular building envelope and system design should be represented in TARP and to assign the appropriate input parameters for a given building.

The resulting expert system is expected to predict infiltration rates for a given building based on past field experience for the general building design amended with as much case-specific information as is made available to the expert system. The expert system will also predict air-flow rates between rates between zones of a building, and may recommend supplemental ventilation if the whole-building or local ventilation rates are anticipated to be excessively low. Alternatives may be recommended for design details that are known to lead to air-leakage problems. 


\section{EXPERT SYSTEM FOR SELECTING CONCRETE FOR JET ENGINE TEST FACILITIES}

James R. Clifton

(301) 921-3458

Building Materials Division

Sponsor: Naval Civil Engineering Laboratory (NCEL)

Port Hueneme, California

The Navy is planning the construction of numerous jet engine test facilities in both the United States and foreign countries. These facilities will be constructed largely from concrete. In the past, the concrete used in such test facilities has frequently deteriorated prematurely. The necessary repairs have been unanticipated and expensive. Many of the concrete failures have been attributed to poor selection of the concrete mixture design, i.e., selection of both the constituents of concrete and their relative proportions.

Expert systems are potentially very useful in making decisions on selection of durable construction materials such as concrete. They can record in knowledge bases the knowledge of experts on the durability of concrete. The knowledge base can then be used to give recommendations at or near the level of human experts, thus facilitating the selection process. The National Bureau of Standards has been developing such an expert system, called DURCON, for selecting the constituents of concrete and their proportions. DURCON can be further developed and its knowledge base modified enabling it to give recommendations on the selection of concrete for jet engine test facilities. The purpose of the proposed project is to further develop and restructure DURCON so that it specifically give recommendations on selecting durable concrete for jet engine test facilities that may be exposed to different service conditions. 


\section{STANDARDS INTERFACE FOR COMPUTER-AIDED DESIGN}

Kent A. Reed

(301) 921-3465

Building Equipment Division

Sponsor: National Bureau of Standards

Computer-aided design ( $\mathrm{CAD}$ ) is critical to the improvement of construction productivity. Computers increasingly are used in producing engineering drawings and related contract documents; however, more extensive use of computers is being slowed by inefficient procedures for checking project-specific design conditions against generic requirements couched within building codes, standards, and project specifications. In particular, designers of commerically available structural engineering software systems have "hard-coded" generic requirements into their programs. As a result, multiple versions of the software systems must be maintained with the codes and standards for different jurisdictions built in. Periodically, these software systems are rendered obsolete as standards-writing bodies alter their requirements. The need to maintain design software current and also applicable across jurisdictional boundaries is critical. With "hard-coded" standards data, this maintenance can be costly.

Current CBT research on the standards interface for CAD suggests that this problem can be mitigated by physically separating generic standards data from checking and other routines within CAD software systems. Previous work at CBT has resulted in the initial elements of experimental standards interface for $\mathrm{CAD}$ and a prototype system based on this concept is under development. In FY84, the University of I1linois Department of Civil Engineering conducted research under grant to define data-mapping techniques for linking generic 
data described in standards with specific data contained in a design project database. Completion of this research and demonstration of a functional standards interface in a CAD environment is essential to the improvement of productivity in building design.

Concepts developed here are expected to reduce significantly the time required to produce more optimal building designs, to make CAD systems less costly to develop and maintain, and to enable the comparative evaluation of building designs under alternative versions of standards.

6 


\section{CONSTRUCTION PROJECT INFORMATION TECHNOLOGIES}

Kent A. Reed

(301) $921-3465$

Building Equipment Division

Sponsor: National Bureau of Standards

Building industry productivity may be enhanced significantly through computer-integration of diverse design, construction, and operating procedures. Impediments to such integration stem from inadequate project information models, lack of formal interfaces between project participants, and lack of standard protocols for representing and describing buildings in a computer-aided design (CAD) environment.

The need for effective data exchange between different CAD systems first was expressed in connection with the manufacture of components for aircraft and other mechanical systems. To mitigate this problem, ANSI has incorporated a version of the Initial Graphics Exchange Specification (IGES) into its standard "Engineering Drawing and Related Documentation Practices -- Digital Representation for Communications of Product Definition Data" (Y14.26M).

In FY84, CBT convened a working group comprising CAD users, CAD vendors, and researchers to explore the need for extensions to IGES for architecture, engineering, and construction (AEC) applications. Based on the recommendations of this working group, CBT coordinated the formation of the IGES/AEC subcommittee responsible for recommending AEC graphic entities and monographic descriptive attributes for IGES. Currently, CBT is the secretariat for this subcommittee. The AEC subcommittee develops recommended practices for applying the current IGES Standard to building problems, techniques and test cases for 
measuring the performance of IGES translator software, and AEC application data models for guiding the development of future versions of the IGES standard. In the long term, the results of IGES/AEC and electronic building project information management, in general, are expected to improve overall productivity in building design and construction. 


\section{BUILDING DATA PROTOCOLS}

Kent A. Reed

(301) 921-3465

Building Equipment Division

Sponsor: National Bureau of Standards

In the last two decades, the use of computers has penetrated every aspect of the building process, including design, construction, and operation. Little integration of these traditionally separate activities has occurred, however, because there exist no effective standards for expressing and interchanging information about buildings beyond the most basic elements. The many participants in the building process continue to be plagued with the errors and inefficiencies that occur because information is not available when needed, is incorrectly transferred, and once transferred, is incorrectly interpreted. Rational techniques for describing building practices and the elements of buildings and their properties are needed to establish the technical bases for interface standards that will support computer integration of the building process.

In this project, earlier work on developing common descriptions of buildings and bulding elements will be reviewed, with particular attention given to the activity of the Architecture, Engineering, and Construction Committee of the Initial Graphics Exchange Specification Committee, and to the Computer Aided Engineering and Architectural Design System under development by the U.S. Army Corps of Engineers. Selected experts from universities and other laboratories will participate in a workshop to define the scope and structure of future data protocols. Preliminary protocols will be developed. A case study of the HVAC equipment and loads in a small commercial building will be conducted to demonstrate and test a portion of the preliminary protocols. 

SPECIFICATIONS

Kent A: Reed

(301) 921-3465

Building Equipment Division

Sponsor: National Bureau of Standards

CBT has sponsored with the Office of Product Standards Policy the development of Standards Analysis, Synthesis and Expression Software (SASE). SASE is built upon the work of CBT researchers and others, and is a systematic method for the analysis of standards, codes, and specifications. SASE now supports key standards analysis work in progress within CBT and is directly associated with other $\mathrm{CBT}$ research on the standards interface for computeraided design, and on the development of expert systems for building design, construction, and operation.

CBT researchers have proof-tested the SASE software in connection with various application tasks, most notably an analysis of ACI 318-1977 (Chapter 4) and a project sponsored by the Federal Trade Commission intended to develop a common format for the model building codes. The proof-testing exercises contributed substantially to an understanding of SASE's capabilities, and led to the formulation of SASE modifications and enhancements.

Development of a portable SASE-software system will be completed in FY85. Known deficiencies in the computer program will be corrected. The code will be brought into conformance with ANSI Fortran-77 specifications to ensure portability and reorganized for easy interfacing with external data-base management systems. The SASE user's guide and associated tutorial materials will be completed. Extension of SASE concepts into the areas of expert systems technology 
and project criteria formulation will be explored cooperatively with researchers at Carnegie-Mellon University.

The SASE technology will provide the building community with a rational and systematic approach to achieving standards that are clear, complete, and consistent. It will also provide a technical basis for CBT work on CAD standards interface, project specifications and information systems, and expert systems. 


\section{CBT INFORMATION MANAGEMENT}

Lawrence J. Kaetzel

(301) 921-2650

Center for Building Technology

Sponsor: National Bureau of Standards

Considerable work involving the centralization of data collection through the use of multi-purpose mini- and micro-computing systems in the CBT Computing Facility has been performed in recent years. Several major software systems were developed to support the processing of management and scientific information in an organized and efficient manner. However, the need to maintain and enhance these systems continually arises due to the dynamically changing research activities. It is essential that new information technologies be evaluated and used to process CBT research data, technical publications, and fiscal information. 


\section{ECONOMIC METHODS FOR BUILDING STANDARDS}

\section{Harold E. Marsha11}

(301) $921-3701$

Center for Applied Mathematics

Sponsor: Nationa1 Bureau of Standards

The building community needs sophisticated, practical methods and guidelines for evaluating alternative building technologies in a consistent manner. The need for standardized, improved methods and guidelines to help the building community achieve affordable buildings that meet performance objectives stems in large part from the rising costs of building materials, the high costs of construction due to safety/environmental regulations, the alleged decline in construction productivity, and the uncertain costs of energy.

Economic methods and supporting analyses will be specially developed for application to building problems. A special publication on handling risk and uncertainty in the economic evaluation of buildings will be produced for use by ASTM in the development of a standard.

The building community will benefit from building economics methods developed at NBS and adopted as recommended practices through the ASTM process by achieving target levels of building performance with lower life-cycle building costs. 


\section{STRUCTURAL LOADS \\ AND \\ RELIABILITY}




\section{DYNAMIC BEHAVIOR OF THREE-DIMENSIONAL STEEL BUILDINGS}

John L. Gross

(301) $921-3146$

Structures Division

Sponsor: National Bureau of Standards

The possible occurrence of a severe event such as strong earthquake or wind must be considered when designing new buildings. Current design practice in regions of high seismic risk focuses on the collapse of the structure as the controlling limit state. Recent studies indicate that incremental collapse must be considered in the design of steel structures located in high seismic areas. The "P-delta effect" has been shown to lead to instability under working loads as a result of severe ground motion. Accurate prediction of the inelastic behavior of steel structures under cyclic loading depends on the realistic modeling of strain-hardening effects. To complicate the situation, it has been - found that three-dimensional inelastic behavior must be considered to capture the important effect of torsion.

Although nonlinear analysis techniques are generally available, they have not found widespread acceptance in design practice largely due to their complexity. Linear elastic analysis methods, which are widely used, often fail to predict accurately the strength and deformation characteristics of complete structures subjected to strong-motion earthquakes. Since such methods are both simple to use and inexpensive, studies will be conducted to correlate computed elastic response and realistic inelastic response of standard types of structures. Guidelines can then be formulated for interpreting results of elastic analyses to predict the strength and deformation characteristics of such structures. 


\section{ANALYSIS OF GENERAL COMBINATIONS OF LOADS}

Bruce E1lingwood

(301) 921-3471

Structures Division

Sponsor: National Bureau of Standards

The prediction of extreme effects of structural loads has improved significantly in recent years as a result of advances in probabilistic modeling of load processes and in load combination analysis. Nevertheless, further research is needed in this area because of the complexity and other limitations of the methods available for load combination analysis. For example, these methods become difficult to apply when three or more loads are acting simultaneously, can treat only linear combinations of independent loads, with a few exceptions, and are generally based on simplistic models developed to capture on1y load extremes.

The research is conducted jointly by CBT and Cornell University. The project continues efforts in the area of probabilistic analysis of structural loads and is attempting to overcome some of the limitations of the current methods for load combination analysis. A major objective of the project is the development of simple and general approaches for approximating the largest value distribution and other descriptors of individual load effects and their combinations.

Eventually, the improved loading criteria would reduce building costs in instances where current provisions are unnecessarily conservative, and would lead to more uniform performance of buildings. Improved load requirements would ensure safety, reduce maintenance, and increase occupant satisfaction. 


\section{CRITERIA FOR STRUCTURAL LOADS AND DESIGN}

Bruce Ellingwood

(301) $921-3471$

Structures Division

Sponsor: National Bureau of Standards

Current structural design standards rely on different approaches to design, depending on the material or construction technology used. This tends to complicate design when different technologies are employed in the same structure. Differences in design philosophy (e.g., ultimate strength vs. working-stress design) and a failure to consider uncertainties explicitly cause a lack of consistency in the reliability and performance of different buildings. Considerable effort has been devoted in the U.S., Canada, and Europe to solving these problems using the unifying concepts of structural reliability theory and probability-based limit states design. There is a need to relate clearly new criteria to existing standards in the U.S. to gain their professional acceptance. This research provides a basis for developing criteria for the design of building structures that will ensure adequate reliability against structural failure and unserviceability and would be appropriate for all materials and construction technologies.

Under this project, engineering variables needed to describe serviceability limit states are being identified from data in the literature and professional experience. Structural load data are being analyzed using time series analysis and other statistical analysis techniques to describe stochastically their 
spatial and temporal variation. Full distribution and advanced first-order, second-moment reliability analysis methods are being used to select appropriate load combinations for serviceability checking. A comparative reliability analysis of structural components and systems is envisioned to determine the extent to which the reliability of individual components differs from the reliability of structural systems considered as a whole. This project will reduce building costs by simplifying the design process and stimulating market competition between construction technologies. Improved serviceability requirements will also result in less maintenance and increased occupant satisfaction. 


\section{DYNAMIC BEHAVIOR OF COMPLIANT OFFSHORE STRUCTURES}

\section{Emil Simiu}

(301) 921-3169

Structures Division

Sponsor: Minerals Management Service

This project will assess the potential of modern structural reliability techniques to estimate nominal failure probabilities of such structures. For selected types of compliant offshore structures, this project will provide detailed mathematical models of loadings, responses, and limit states that may occur as a result of their dynamic behavior under wind and wave action.

Researchers will review fundamentals, practical methodologies, and computer programs pertaining to structural reliability, and will maintain close contact with the American Bureau of Shipping, Det Norske Veritas, the Navy Department, and other agencies with an interest in structural reliability of compliant offshore structures under dynamic loads. This research will assist the Minerals Management Service in ensuring acceptable risks to the public as far as the safe operation of compliant offshore structures is concerned. 


\section{PUNCHING SHEAR STUDY OF REINFORCED SHELL}

H.S. Lew

(301) 921-2647

Structures Division

Sponsor: Minerals Management Service, Dept. of Interior

Concrete offshore structures offer great potential for the safe and economical development of mineral reserves in the Artic region. Such structures may experience high concentrated loads from ice with intensities in the range of 100 tons/sq ft. (10MPa). Under such a high intensity load, the outer shell, which serves as the ice wall, may experience punching shear failure. Experience has shown that if designed in accordance with existing guidelines, the exterior shells would become very thick so that it would not be possible to tow the structures through relatively shallow waters. At the present time there are no rational criteria available for the design of thick and heavily reinforced concrete shells, particularly of lightweight concrete subjected to high intensity concentrated loads.

The performance of concrete shell elements subjected to high local forces will be studied. The behavior of shell and plate elements will be studied using small scale physical models. Tests will be made on 1/6-scale and 1/3-scale models to study the size effects. The experimental program will be supplemented with analytical studies to predict the expected performance of the test specimens. The analytical models will simulate the multi-axil stress states within thick members and will incorporate non-linear material behavior. Full-scale tests will be conducted to verify the analytical model. 


\section{MAT FOUNDATION FOR OFFSHORE GRAVITY STRUCTURES IN ARCTIC REGIONS}

Felix Y. Yokel

(301) 921-2648

Structures Division

Sponsor: Mineral Management Service

Offshore gravity structures planned for the Beauford Sea must survive a hostile environment. The structures will be built in moderate ocean depth ( $60 \mathrm{~m}$ range) and will rest on mat foundations. There is no past service record for designing these structures. The structures will have to resist large dynamic environmental loads including ice thrust and ice floe impact, waves, wind, and earthquake. Difficult soil conditions will be encountered, including unstable deposits which are frozen but close to the melting point and thus sensitive to minor changes in thermal regime. Little is known about the problems associated with these deposits, such as characteristics of permafrost in a saline environment and possible effects of gas hydrates under melting conditions. Other problems include bottom irregularities resulting from ice guaging and soil liquefaction caused by wave action and other dynamic loads.

CBT will conduct a state-of-the-art study and a review of planned design procedures. Gaps in knowledge and data base will be identified. Design limit states will be identified and defined. An assessment will be made of uncertainties with the determination of load and resistance parameters. 


\section{RELIABILITY OF WOOD STRUCTURES}

Erik Hendrickson

(301) 921-2186

Structures Division

Sponsor: National Bureau of Standards

This project is aimed at developing practical resistance criteria for limit states design of engineered wood structures, taking into account random variations in strength and creep-rupture behavior. The research will focus on developing probabilistic design criteria for glue-laminated and engineered heavy-timber structural elements. This type of construction competes with, and can be considered, in some cases, a viable alternative to reinforced concrete and steel construction.

Statistical descriptions of the strength of wood will be based on existing and newly acquired strength data obtained from the Forest Products Laboratory's In-Grade Test Program. This response of structural wood elements to random live, snow, wind, and dead load will be considered. Probability laws for the extremes of these loads and their variation in time will be investigated for potential use in reliability and cumulative damage analyses. The strength analyses to determine the effect of loads must account for the creep-rupture phenomena in wood. Various load duration models and damage accumulation theories will be examined to discover which model may be best and to examine the effects of using different models. The development of a probability-based limit-state design for wood will help make wood design more compatible with other types of construction and encourage its use as an engineered construction material. 


\section{CRITERIA FOR DESIGN OF CLADDING SUBJECTED TO WIND LOADS}

Emil Simiu

(301) 921-3169

Structures Division

Sponsor: National Bureau of Standards

Modern analytical and experimental tools from the fields of wind engineering (aerodynamics of bluff bodies in turbulent boundary layer flows), nonlinear mechanics of plates, structural reliability, and materials testing will be used in this project with a view to developing rational criteria for cladding design. Data from full-scale and wind-tunnel investigations of wind loads on cladding will be reviewed and studies will be conducted to determine the effect of pressure time history (including frequency content) on glasscladding load capacity. Results obtained at CBT concerning the feasibility of inferring glass cladding load capacity from testing of small glass samples will be used to demonstrate the practical applicability of this approach.

This research will be of use to the cladding industry and to codes and standards organizations and Federal agencies charged with developing criteria for reliability and serviceability of structures. It is anticipated that the results will be presented to the glass industry with a view to securing its involvement in CBT research. Consistent design procedures will reduce economic losses and the number of accidents due to cladding damage in windstorms, and will lead to improved economy by reducing overdesign in instances where current provisions are unnecessarily conservative. This work also could lead to revisions of ASTM Standard E330 dealing with standard test methods for exterior glazing and curtain walls. 
BEHAVIOR OF GLASS CLADDING SUBJECTED TO WIND LOADS

Emil Simiu

(301) 921-3169

Structures Division

Sponsor: National Science Foundation

This project will obtain data on the magnitude of the constants in the relationship between rate of subcritical crack growth and stress intensity, and on the probability distribution of initial glass strengths. A reliabilitybased format for designing glass cladding for wind loads will be developed that accounts realistically for both load and strength variability. Consistent design procedures will reduce economic losses and the number of accidents due to cladding damage in windstorms, and will lead to improved economy by reducing overdesign in instances where current provisions are unnecessarily conservative. This work also could lead to revisions of ASTM Standard E330 dealing with standard test methods for exterior glazing and curtain wa1ls. 


\section{PROBABILISTIC RISK ASSESSMENTS OF TORNADO MISSILE DAMAGE}

Emil Simiu

(301) 921-3169

Structures Division

Sponsor: Nuclear Regulatory Commission

Among the possible causes of damage to nuclear power plants is the impact of objects, usually referred to as missiles, that are propelled by tornado winds. The Nuclear Regulatory Commission (NRC) requires that the probability of tornado-borne missiles attaining critical speeds and hitting nuclear-power plants should not exceed $10^{-7}$ in any one year. This project is concerned with assessing reports submitted by utilities to NRC concerning the effect of tornadoes on the safety of various components of nuclear power plants.

The assessments will be carried out using probabilistic, statistical, and numerical simulation tools, as well as information concerning frequency of occurrence and physical characteristics of tornadoes, and aerodynamic characteristics and potential number and location of objects susceptible of becoming tornado-borne. This work will assist NRC in ensuring acceptably small risks of accident in the operation of nuclear-power plants. 


\section{CBT WIND TUNNEL}

Richard D. Marsha11

(301) 921-2170

Structures Division

Sponsor: National Bureau of Standards

This project will support the aerodynamic and structural design of a NBS/NSF regional boundary-layer wind tunnel and liaison with the NBS Plant Division concerning space modification, coordination of equipment procurement, and construction contracts. The effort also will consider mechanical engineering applications for the completed facility. Facility design will be based in part on test data obtained from previous studies carried out on $1 / 4-$ scale components of the proposed tunnel, and on the recommendations of an NSF-supported advisory committee. This new facility, based on performance criteria, will enable CBT to address important problems in several areas of building technology. In addition to providing new opportunities for competence development, it will also enable CBT to more effectively respond to the research needs of other Federal agencies. 


\section{STRUCTURES/MECHANICAL DESIGN CRITERIA FOR LOW-IMPACT RESISTANT STRUCTURES (LIRS)}

Spencer Wu

(301) 921-2186

Structures Division

Sponsor: Federal Aviation Administration

The potential hazard of an aircraft colliding with approach lighting structures during landing or take-off operations has led FAA to investigate the possibility of developing a structural system with low impact resistance. The goal of designing LIRS is to impart minimum damage to aircraft in the event of an accidental collision. "Breakaway" mechanisms in structural systems have been considered by FAA to meet this need. But to ensure the effectiveness of such a system, the characteristics of the structural systems (including components such as the electrical conductors) need to be investigated. Analytical models for the numerical simulation of LIRS subjected to aircraft impact are also needed.

This research program will consist of three separate activities. Activity I is to investigate the behavior of electrical conductors by performing static and dynamic pull tests of these conductors used for approach lighting LIRS. Activity II involves the analysis, erection, and testing of an antenna support structure. Activity III will be devoted in the development of analytical models for the prediction of response of LIRS subjected to aircraft impact. This research will improve the understanding of the impact phenomenon and support the development of design criteria for LIRS. 


\section{RELIABILITY-BASED DESIGN OF CONTAINMENTS AND CATEGORY I STRUCTURES}

Bruce E11ingwood

(301) 921-3471

Structures Division

Sponsor: Brookhaven National Laboratory (BNL)

The unpredictable nature of the possible loads on nuclear power structures and uncertainties in structural properties and behavior mandates a probabilistic approach to an assessment of structural safety and performance. Structural reliability theory has been applied to earthquake engineering, wind engineering, ocean engineering, aerospace structures, and to the development of load factors, load combinations, and resistance factors for ordinary building construction.

In the nuclear industry, there also has been a trend toward the use of statistical analysis and probability theory for safety evaluations. Rational methods for reliability evaluation of strength and loads are urgently needed. Structural designers and regulatory authorities will take advantage of these methods if they do not lead to significant additional complexities at the design level.

Under this joint project with Brookhaven National Laboratory (BNL), CBT has responsibility for the analysis of service and extreme environmental loads and for developing the basic design load-combination methodology. BNL has responsibility for analyzing accidental loads, postulating accident scenarios, dynamic structural analysis of the nuclear structures, and testing the design procedure. Probability-based load and resistance criteria are being developed for concrete contaminants and shear wall structures. These new probability- 
based procedures should enable designs to be obtained in which the associated risk of unsatisfactory performance is realistic and consistent with the objectives of the regulatory authority. 


\title{
STRUCTURAL CONDITION ASSESSMENT STANDARDS
}

\author{
James H. Pielert \\ (301) 921-3481 \\ Building Materials Division \\ Sponsor: National Bureau of Standards
}

Throughout the U.S., there is increasing concern about the need to more fully use the existing building stock. The commercial and residential renovation and rehabilitation markets are each currently in the $\$ 50$ billion per year category. The building rehabilitation process requires many technical decisions by designers, builders, and building officials relative to the condition of existing buildings. But the data needed to make these conditionassessment decisions are broadly dispersed and not readily accessible. It is necessary to subject such information to a consensus review and provide the design community with resource standards on building condition assessment for selected materials (concrete, metals, masonry, wood, etc.).

Technical support to the ASCE Standards Committee on Structural Condition Assessment will include preparation of standards outlines and draft information based on CBT and other relevant research, providing CBT staff support to technical issues as appropriate including review of draft standards, and coordination with other related standards activities (ASTM, ACI, etc.). Administrative support will include providing a chairman to the committee, organization of committee membership, holding two meetings of the ful1 committee, and ensuring that ASCE standards process be followed. This project will result in a more uniform approach to building rehabilitation and more efficient use of the existing building stock. 


\section{PULSE ECHO FOR FLAW DETECTION IN CONCRETE}

Nicholas J. Carino

(301) 921-3146

Structures Division

Sponsor: Office of Nondestructive Evaluation

Presently there is no satisfactory method to locate internal defects in concrete structures. The pulse-echo method, which is based on the interaction of stress waves with internal discontinuities, has the potential to fill this need. However, before this method can be implemented, a fundamental understanding is required of how stress waves propagate through and interact with flaws in a heterogenous material as concrete.

The objective of this research is to gain a fundamental understanding of the interaction of stress waves with internal discontinuities in concrete structures. Such knowledge is required to develop test methods and proposed standards for using the pulse-echo technique for nondestructive evaluation of the internal condition of existing concrete structures.

A research program was initiated in FY 1983 to develop the needed knowledge to implement the pulse-echo technique. In FY 1984, experiments demonstrated the feasibility of using a pulse technique based on a pointsource and a point receiver to locate planar defects in concrete. In FY 1985, the research will investigate the feasibility of the pulse technique to locate realistic defects in concrete specimens. 


\section{NDT METHODS FOR CONCRETE}

Nicholas J. Carino

(301) 921-3146

Structures Division

Sponsor: National Bureau of Standards

Despite advances in concrete technology, there is no satisfactory method for locating internal defects in hardened concrete structures. The need for this capability is increasing with the current national emphasis on rehabilitation of existing structures and on quality-acceptance systems. The pulse-echo method has the potential to fill this need if a fundamental understanding of wave propagation in concrete can be achieved, and if standards are developed for using the technique.

In pulse-echo testing the most common techniques for introducing the stress pulse are with an electrical transducer or by mechanical impact. A transducer produces essentially plane waves that propagate through the material and are reflected by interfaces. However, a satisfactory transducer for sending pulses into concrete does not exist. The impact technique that produces spherical waves is attractive because of its simplicity, but signal interpretation is more difficult than with the transducer source.

In FY84, the main objectives of this work were to investigate the feasibility and reliability of the impact technique and to develop an appropriate transducer source. From tests on a large concrete slab containing known defects, it was shown that under the correct conditions the impact technique was capable of locating the defects. It was found that the two essential items are a highfidelity receiving transducer and impact with a short contact time. Numerical 
solutions for an infinite plate were carried out and the results aided in interpreting the experimental signal traces.

Based on the encouraging results obtained with the point-source-point receiver impact method, one of the objectives of the FY85 effort will be to develop a source and recelver that can be used under realistic field conditions. In addition, signal-processing techniques will be investigated to enable easier interpretation of the signal records. A new concrete specimen containing realistic concrete defects, such as cracking, honeycombing, and reinforcing steel, will be fabricated for evaluating the test method. Work on this project will be a cooperative effort involving CBT and the Korean Standards Research Institute. 


\section{GEOTECHNICAL ENGINEERING}




\section{STANDARDS FOR FOUNDATIONS AND EXCAVATIONS}

Felix Y. Yoke1

(301) 921-2648

Structures Division

Sponsor: National Bureau of Standards

Even though most structural failures and distress are associated with inadequate foundations and very large sums of money are invested in excavation work, there is currently no national standard for foundations and excavations in the U.S. As a consequence, effective code regulations are either absent or differ from location to location, causing difficulties and confusion in the introduction of new technologies and in the application of standards systems.

CBT assists the American Society of Civil Engineers in the development of standards for foundations and excavations by serving as a secretariat for the Committee on Foundation and Excavation Standards and supporting the activities of the working committees by providing leadership and technical input. Pending availability of adequate financial resources, CBT will also take the initial steps in the development of a probabilistic code format for foundation and excavations. Additionally, CBT provides the technical basis for standards developed by other agencies outside the ASCE. At the present time these include: Mobile Home Foundations (ANSI A225) and Excavation Safety (OSHA, an eventually ANSI A10.12), and will probably extend into areas of geotechnical in-situ measurements and laboratory testing. 


\title{
SOIL TEST PROBE
}

\author{
Felix Y. Yoke1 \\ (301) 921-2648 \\ Structures Division \\ Sponsor: Tri-Services Committee
}

The problem of soil exploration at shallow depths (less than $3 \mathrm{~m}$ ) has been generally neglected by the geotechnical profession. Existing methods for use at these depths are either inaccurate or too expensive. Since most residential structure foundations and utility lines are located at shallow depths, there is a need for an accurate, practical, and inexpensive method of exploring and classifying soils at shallow depths.

During a study of soil anchors, CBT identified an ideal tool for this purpose consisting of a small diameter helical screw that can be inserted by one man. The torque necessary to turn the screw can be correlated with the shear strength of the soil. In the first stage of the project, three sizes of test probes for different soil strengths will be built, and test probe readings wi11 be correlated with cone penetrometer, plate loading, and laboratory tests. This will enable CBT to model and calibrate the device. In the second stage, operational prototypes will be built and design charts for practical applications will be prepared. Use of the soil test probe will substantially reduce the cost and improve the quality of site exploration and foundation design. For inaccessible sites, it also will result in improved reliability, of foundation performance, since other exploration methods may not be feasible. 


\section{EVALUATION AND EXPANSION OF LIQUEFACTION DATA BASE}

Riley M. Chung

(301) 921-2648

Structures Division

Sponsor: National Science Foundation

The purpose of this research is to better define and expand the data base linking insitu measurements by the Standard Penetration Test (SPT) and the Cone Penetration Test (CPT) with the determination of the liquefaction potential or cyclic mobility of sites with saturated granular soils.

The project was coordinated to coincide with the exploration of Japanese sites where liquefaction occurred on May 26, 1983. Results of the study enabled CBT to compare U.S. and Japanese SPT liquefaction data base. It will enable CBT to establish energy ratio that can be used to normalize all the liquefaction SPT data throughout the world. These data bases can then be applied to re-assess and, if necessary, revise the existing liquefaction resistance design curves. 


\section{EARTHQUAKE}

\section{ENGINEERING}




\section{William Stone}

(301) 921-2198

Structures Division

Sponsor: California Department of Transportation

National Science Foundation

National Bureau of Standards

Federal Highway Administration

A national workshop on Earthquake Resistance of Highway Bridges held in January 1979 identified research needs and established priorities in the area of seismic aspects of highway bridge design. One of the highest priority research needs identified was to determine the effects of scale factor on bridge column design to determine whether the behavior of small sections can be extrapolated to large cross sections and to examine the performance of selected full-scale details.

This project will determine the influence of size (scale factor) on the seismic performance of columns. Experimental programs on large-scale specimens are expensive and difficult to conduct; hence, the limited availability of data in the literature. Careful planning of a test program will produce much needed full-scale performance data over a range of axial loads and column designs. Such a range is necessary to examine the effect of scale factor since such an effect will likely be dependent on the column mode of failure. CBT will examine the behavior of approximately $1 / 6$ scale test specimens. The scale tests are expected to identify problems of scale effect. If necessary, a complete examination of scale effects will be possible in the future using the data obtained in this research.

The research will provide a technical base that is currently unavailable to determine if there is scale effect for very large cross section columns. 
INELASTIC PERFORMANCE OF STEEL-BRACED FRAME CONNECTIONS

John Gross

(301) 921-3146

Structures Division

Sponsor: National Bureau of Standards

This project will study the gusset plate behavior and the connection of braced elements with columns and beams in steel frames. The investigation will involve experimental testing of planar-braced steel frames. The selection of specific variable and specimen design will be coordinated with analytical studies in progress at the University of Arizona. The experimental tests will provide vitally needed information that is not presently available and will serve as the basis for validation of mathematical models being developed. 


\section{CYCLIC STRAIN APPROACH TO DETERMINING THE LIQUEFACTION POTENTIAL OF LEVEL SANDY SITES}

Riley M. Chung

(301) 921-2648

Structures Division

Sponsor: National Bureau of Standards

The object of this study is to determine the correlation between cyclic strain, excess pore-water pressure buildup, degradation of shear modulus, increase of damping ratio, and associated volume change for silt and silty sandy soils, and to develop a new design approach (or modify present design methods) based on these correlations. Current laboratory work on silty soils will be expanded to include variables such as confining pressure, density, overconsolidation ratio, and number of strain cycles to: (a) determine the threshold strain value, and (b) develop proper material models for the silty soils required for seismic response analysis. The work should also include a thorough literature review of the seismic analysis methods to pave the way for the planned analytical work in FY86 and beyond.

Results of this research will be passed on through design provisions and standards, publication in technical journals, presentation at technical meetings, and by adoption of new methods of engineering analysis by agencies such as the Nuclear Regulatory Commission, the Bureau of Reclamation, and the Federal Highway Administration. It will also serve as the basis for further research in geotechnical earthquake engineering. This research will also lead to a new, more reliable method of determining liquefaction potential, cyclic mobility, and seismically induced settlements of level sandy and silty sites. 


\title{
CYCLIC LOADING OF MASONRY BUILDING COMPONENTS
}

\author{
Kyle Woodward \\ (301) 921-2160 \\ Structures Division \\ Sponsor: National Bureau of Standards
}

The process of developing tentative seismic design provisions for both unreinforced and reinforced masonry building components reveals a scarcity of information on ultimate strength characteristics. Since seismic resistance is now based primarily on ultimate strength considerations, the lack of such information for masonry is detrimental to rational design of buildings subjected to seismic loadings. Here, experimental tests will provide vitally needed information not now available that will serve as the basis for development of mathematical mode1s. The characteristics of a number of failure modes will be examined to identify the significant parameters affecting each.

Analytical expressions for predicting fallure as a function of key parameters will be developed. Later experimental testing will determine the generality of the proposed analytical expressions. This research will provide engineers with a sound base not currently available by presenting experimentally verified rational approaches for ultimate strength design. 


\section{SEISMIC SAFETY IN CONSTRUCTION}

E.V. Leyendecker

(301) 921-3471

Structures Division

Sponsor: Federal Emergency Management Agency

The Federal Government must set an example for others to emulate by its own actions, including the institution of more effective hazards mitigation measures in its own facilities. In recognition of these needs, the Congress passed the Earthquake Hazards Reduction Act of 1977 (P.L. 95-124), and the President established the National Earthquake Hazards Reduction Program (NEHRP) the following year. The NEHRP established the Interagency Committee on Seismic Safety in Construction.

The purpose of the Interagency Committee on Seismic Safety in Construction (ICSSC) is to assist the Federal departments and agencies involved in construction to develop and incorporate earthquake hazards reduction measures in their ongoing programs. These will be based on existing standards when feasible and will be consistent with OMB guidelines.

NBS will provide technical and administrative support to the activities of the ICSSC that are aimed at meeting the Committee's specific objectives. Specific objectives cited in the NEHRP include:

- develop seismic design and construction standards for Federal projects

- develop guidelines to ensure serviceability, following an earthquake, of vital facilities constructed or financed by the Federal Government,

- develop guidelines that provide for independent State and local review of seismic considerations in the construction of critical facilities constructed and financed by the Federal Government where appropriate, 
- develop guidelines for including earthquake hazards reduction activities in ongoing Federal programs,

- develop a strategy to identify existing Federal buildings and other structures that pose unacceptable earthquake-related risks,

- coordinate the development of guidelines for the consideration of seismic risk in the development of Federal lands.

ICSSC will cooperate with State and local government and private organizations in developing nationally applicable earthquake hazard reduction measures. Using consensus procedures, the ICSSC will recommend earthquake hazard reduction practices suitable for use by Federal agencies. ICSSC recommended practices will not be mandated for use by Federal agencies except by Executive order, but they may be adopted as required practices by the various Federal agencies following their established practices for implementing regulations. 


\section{TECHNICAL ASSESSMENT OF EARTHQUAKE-RESISTANT DESIGN PROVISIONS}

E.V. Leyendecker

(301) $921-3471$

Structures Division

Sponsor: Federal Emergency Management Agency

This project is a continuation of work with the Building Seismic Safety Council (BSSC) in its effort to support improved seismic design criteria. CBT will provide support as the technical secretariat of the BSSC Trial Design Overview Committee which is working on resolution of technical issues resulting from the BSSC ballot on the Tentative Seismic Design Provisions. These tentative seismic design provisions prepared by the Applied Technology Council, a group affiliated with the Structural Engineers Association of California, were published in 1978. The work was based substantially on CBT's effort. In 1980 and 1981 CBT developed and headed a project to review and refine these provisions. The results of this review and proposed revisions were presented to the Building Seismic Safety Council, a national body whose goal is to improve the public safety through improved seismic design, for their consideration and subsequent use in conducting trial designs for evaluation purposes. The amended design provisions have been evaluated through a national trial design program and submitted to BSSC membership for approval.

CBT will work with a panel of experts to identify new research and practical experiences ready for incorporation into revised design provisions. High priority technical areas (one or more) will be selected and remaining technical problems resolved.

Results of this effort will include preparation of possible "code" provisions for seismic design. These will be available for consideration by BSSC and others. 


\section{THERMAL ANALYSIS AND MEASUREMENTS}




\section{EVALUATION OF THERMAL ANOMALIES}

Richard A. Grot

(301) 921-3501

Building Physics Division

Sponsor: Department of Energy

Thermographic inspection of insulated buildings often shows that there are thermal anomalies in the insulation system from improperly installed insulation, convective air movement in the insulation, and moisture damage to the insulation. At present there is no method for quantifying the heat loss due to these anomalies so that the impact of correcting the anomalies can be judged.

This project will investigate the adequacy of several in-situ methods for quantifying the heat losses due to thermal anomalies. The use of thermography will be assessed for quantifying temperature and heat flux. Laboratory tests will be performed on representative thermographic systems to determine their characteristics for making quantitative measurements. The in-situ use of heat flow meters and calorimeter boxes for measuring the heat losses due to thermal anomalies will be investigated. Guidelines will be established for each of these methods and an assessment of their accuracy will be made. This project will enable building researchers and diagnosticians to determine the severity of heat loss due to thermal anomalies in the building envelope and thus give a sound basis to recommend remedies. 


\section{HEAT LOSSES THROUGH THERMAL BRIDGES}

Richard A. Grot

(301) 921-3501

Building Physics Division

Sponsor: Department of Energy

As buildings become more insulated, the heat loss due to structural members becomes significant and can degrade the performance of the insulation system by about 10 to 20 percent. These parts of the structure may also experience condensation and thus become potential sources of building deterioration. Current analyses and models of the building envelope ignore the presence of thermal bridges.

Methods for detecting the presence of thermal bridges will be developed. Generic types of thermal bridges will be analyzed using the Oak Ridge National Laboratory "Heating 6" finite difference heat transfer program. In-situ measurement methods for quantifying the heat loss from thermal bridges will be developed. This method will include the use of heat flow meters and calorimeter boxes for measuring the heat loss due to the thermal bridge and the heat loss of the insulated wall section. The data will be analyzed to determine the degradation in performance of the insulation system due to thermal bridging. The results will be compared with the theoretical predictions of "Heating $6 . "$ 


\section{AIR INFILTRATION AND VENTILATION IN LARGE BUILDINGS}

Richard A. Grot

(301) 921-3501

Building Physics Division

Sponsor: Department of Energy

Availability of a consensus measurement method for evaluating ventilation efficiency will give building designers, owners, and users a tool for measuring the energy efficiency with which ventilation systems achieve an effective level of contaminant removal. A useful relationship between pressurization and infiltration in commercial buldings will enable the use of pressurization testing to evaluate different building designs and the effectiveness of shelltightening retrofits.

In this project, test methods already developed for measuring the efficiency of ventilation will be applied to modern commercial buildings. These methods will determine the amount of air exchange that is effective in removing contaminants from the work space. The methods are based on the injection of tracer gas into various zones of the building and determination of the buildup and decay of the tracer gas in the work space and in the exhaust air. Initially the CBT automatic air infiltration system developed for application to large buildings will be used. The procedure will be evaluated by testing at least three different commercial buldings and using the results to determine the effectiveness of the ventilation systems. In addition, CBT will continue the collection of air infiltration and ventilation data in three large commercial buildings that have passive solar design features and large atria. Fan pressurization tests will also be conducted on these buldings to study the relationship between air tightness measurements using fan pressurization and infiltration measurement using tracer gas. 


\section{THERMAL MODELING OF BUILDINGS}

\section{George Walton}

(301) $921-3633$

Building Physics Division

Sponsor: National Bureau of Standards

CBT has developed the Thermal Analysis Research Program (TARP), which can predict the interzone heat transfer and interzone movement of air, moisture, and contaminants. Under this project, the accuracy of this model for predicting air infiltration and interzone air movement in large buildings will be investigated using data collected by CBT's automated air infiltration system. Development of a multi-tracer interzone air infiltration system will be completed and used to collect interzone air movement data in two large buildings. A simple model will be developed for the inclusion of thermal bridges into the computer model. 


\section{EVALUATION OF AN ENVELOPE THERMAL TESTING UNIT}

Richard A. Grot

(301) 921-3501

Building Physics Division

Sponsor: Oak Ridge National Laboratory

Presently there are no rigorous assessments of in-situ measurement methods for determining thermal resistance. The Department of Energy has designed and fabricated a prototype thermal envelope testing unit which in principle is capable of measuring the dynamic response of walls.

CBT will determine the usefulness and accuracy of the envelope thermal testing unit (ETTU) developed by the Lawrence Berkeley Laboratory for the Department of Energy. The device will be used on CBT field projects to determine the practical problems and field sources of errors resulting in its use. Guidelines will be developed for using the ETTU. Measurements will be made in the six CBT thermal mass buildings and the results compared with the known thermal resistance of these walls. A series of test walls of typical construction will be built and installed in a small test cell in the environmental chamber. Measurements will be made on these wails under various simulated thermal conditions. These walls can be later tested in the CBT guarded hot box. From these tests the accuracy of ETTU will be determined under various environmental conditions. The sources of error will be determined and the results compared with those of other test methods.

The data and guidelines resulting from this project will be offered to ASTM and ASHRAE as a basis for possible development of a standard test method or for the inclusion in the ASHRAE Handbook series. 


\section{MEASUREMENT AND MODELING OF FENESTRATION OPTICS}

George Walton

(301) 921-3633

Building Physics Division

Sponsor: Department of Energy

This research will develop a general procedure for modeling the optical performance of windows in building energy and daylighting analysis programs. It also will propose and demonstrate a test procedure which would determine the coefficients used by the window optical model.

Windows have a major impact on the energy requirements of most buildings. Solar gains may greatly decrease heating loads or increase cooling loads and daylight can be used to decrease lighting and cooling loads. Solar gain and daylight calculations should be closely related since they deal with different wavelength distributions of the same solar spectrum, but there is no unified approach to the modeling of windows.

The research will begin with a thorough review of theoretical optics for detailed fenestration calculations, simplified analysis procedures, and test methods. Theoretical models of several window systems will be developed using detailed optics. These will be compared to the existing simplified algorithms in terms of the impact on predicted building energy requirements. In ensuing years, additional simplified algorithms will be developed for innovative window systems. The accuracy of a method for simulating a complex multilayered window based on the properties of the individual layers will be tested.

This research will produce algorithms for modeling the optical performance of windows, a general optical model of windows, a test procedure for determining coefficients for the model, and the demonstration and validation of the test procedure. 


\section{GLAZING TEMPERATURE MEASUREMENT}

Stanley Liu

(301) 921-2607

Building Physics Division

Sponsor: National Bureau of Standards

This project will assess the accuracy of thermal-contact the rmometry and radiation pyrometry to measure glazing temperature under irradiated conditions and evaluate unique temperature measurement techniques for glazing materials.

A literature search on recent temperature measurement techniques for solid transparent bodies will be conducted. The accuracy of thermal contact thermometry and radiation pyrometry to measure glazing temperature wil be determined. Unconventional techniques to measure glazing temperature will be evaluated. Among these are multiple sensors of various sizes, the use of strain gages, the use of changes in properties of a single glazing as a function of temperature, and the use of thermocouple shields.

The results will give solar equipment designers an accurate test methodology for solar collectors and passive solar glazing components and systems. The method will also aid in the measurement of glazing surface temperatures for use in convective heat-transfer coefficients in building-energy calculations. 


\section{THERMAL PERFORMANCE OF FENESTRATION SYSTEMS}

Michael E. McCabe

(301) 921-2308

Building Equipment Division

Sponsors: DoE Building Systems Division

DoE Passive Solar Division

This project will identify and quantify the surface heat transfer mechanisms which occur in building fenestration systems under laboratory and field conditions. Also, this research will develop a technical basis for a standard laboratory test method for measuring heat transfer rate data for use in calculating building energy requirements.

This research involves two phases. In Phase 1 , research is aimed at developing a proposed technique to measure surface heat transfer coefficients and experimentally measure the variation in U-value with wind speed and ambient temperature. This will be undertaken in a cooperative effort with the University of Massachusetts at Amherst. The results of this project will be submitted to a joint task group within ASTM to draft a standard test method describing the specific equipment and measurements to be taken for determining the U-value (overall transmittance) and C-value (surface conductance) of various types of building assemblies, including fenestration systems and to draft a standard practice that describes the specific test conditions, mounting provisions, preconditioning requirements, and calculation procedures for analyzing fenestration system test data obtained using the Standard Test Method.

In Phase 2, activities will focus on assessing the need for measurements on fenestration of representative geometries, reveals, etc. Field testing will be performed of the HFM/SGU test articles using the Lawrence Berkeley 
Laboratory facility at selected field sites suitable for both wintertime and summertime climatic conditions and the passive solar calorimeter. Field test results will be compared with laboratory test results to determine the laboratory testing procedure that best correlates with the field test results. 


\section{THERMAL MASS - EFFECT ON RESIDENTIAL COOLING AND HEATING LOADS}

Douglas M. Burch

(301) 921-3754

Building Physics Division

Sponsor: Electric Power Research Institute

The objectives of this project are three: (1) to analyze previously measured test results of the NBS thermal mass test buildings to investigate the effect of building envelope and building operation parameters on reducing and delaying peak space heating/cooling loads; (2) to investigate the effect of the thermal mass of the interior partition walls and interior furnishings on reducing and delaying peak summer cooling loads; and (3) to compare space heating/cooling loads predicted with two computer programs called EMPS and TARP to corresponding measured heating/cooling loads.

High peak electrical utility loads make it necessary for the public utility companies to install larger and more expensive electrical generating equipment in power plants. In addition, high peak loads often cause more expensive fuels to be consumed during peak load periods. Public utilities are interested in investigating innovative ways to construct and operate buildings to reduce the peak electrical load on the utility.

Using previously measured test results from CBT's six, one room thermal mass test buildings, the effect of wall mass, wall insulation, thermostat set temperature, and special operation modes (including night ventilation cooling and winter night termperature setback on reducing and delaying peak space heating/cooling loads will be analyzed.

A conventional wood-frame partition wall will be installed in an uninsulated wood-frame building and an uninsulated masonry building. The partition walls will divide the interior spaces of these buildings into equal size rooms of 
equivalent floor space connected by a door. These two buildings will subsequently be exposed to an 8-week summer cooling season. Interior furnishings consisting of office furniture will be installed in the woodframe building during a 3-week period of the summer cooling season. The effect of partition walls and interior furnishings will be assessed by comparing these peak cooling load correlations to corresponding correlations without interior mass features present.

Fourteen-day data files containing measured outdoor weather parameters will be created for the previously measured winter heating season, intermediate heating season, and summer cooling season. The last three days of these files will contain measured heating/cooling loads and indoor temperatures for the six test buildings. During these measurements, the buildings did not contain partition walls and interior furnishings. For each of these 14-day data files, heating/cooling loads will be predicted using TARP and EMPS computer programs and w111 be compared to corresponding measured heating/cooling loads. Similar comparisons will be carried out using the summer partition wall and interior furnishing test results. After EMPS is validated it will be used to investigate the effect of wall mass and interior mass features on the peak heating/cooling loads and annual heating/cooling energy consumption for a typical residence. 


\section{FIELD MEASUREMENTS OF WALL THERMAL MASS}

Douglas Burch

(301) 921-3754

Building Physics Division

Sponsor: Department of Energy

There is a real need to measure and experimentally evaluate the energy savings attributable to thermal mass in buildings, so that present energy conservation standards can be modified where appropriate to reflect benefits realized from thermal mass. The FY84 report on partition wall tests was deferred into FY85. This was necessary because the field partition wall measurements using the test cells were unrepresentative of the thermal performance of typical residential buildings because the solar gains for the test cells were very small. To extend the field measurements into typical house situations, CBT's computer model TARP will be used to analyze partition wa11 effects in a well insulated residential prototype and a poorly insulated residential prototype. The validation of TARP will compare measured space heating/cooling loads for the test cells with corresponding predicted loads using the TARP program.

The experimental field data reported will provide a preliminary validation of calculation procedures for predicting the impact of wall thermal mass on residential residences in selected climates. The results will enable HUD, DoD, FmHA, ASHRAE, building designers, and materials trade associations to perform credible evaluations of the cost-effectiveness of various design and material strategies. Recommended delta-R values will provide guidelines in the interim. 


\section{TRANSIENT HEAT TRANSFER CHARACTERISTICS FOR WALLS}

Douglas M. Burch

(301) 921-3754

Building Physics Division

Sponsor: Department of Energy/Oak Ridge Nationa1 Laboratory

Calibrated hot boxes have previously shown poor agreement between measured specimen heat transfer and corresponding predicted values using dynamic heat transfer models when the wall specimen is subjected to time-varying boundary conditions. The lack of agreement is largely due to measurement errors in the specimen heat transfer caused by failure to account for time-varying flanking heat transfer through the frame around the wall specimen. Another problem is each laboratory uses a different time-varying outdoor boundary condition and reports the heat-flow response at the inside specimen surface. As a result, the heat-flow responses measured by the various laboratories cannot be usefully compared.

Under this project, monolithic and homogeneous wall specimens having known thermal resistance will be installed in the $\mathrm{CHB}$. The metering and climatic chambers will be operated at steady temperature conditions. The feasibility will be investigated to empirically determine the conduction transfer functions (CTFs) for the flanking loss.

The feasibility of developing conduction transfer functions (CTFs) for flanking losses and wal1 heat transmission will be determined. The availability of CTFs will provide techniques for predicting time-varying performance of wall systems when exposed to dynamic thermal conditions. The CTFs and the concept of their use will be made available to the design profession. Designers and engineers will be more able to predict 
accurately the dynamic thermal performance of wall systems. The ability

to better predict performance will allow designers to assess and recommend energy-conserving system designs. 


\section{HEAT TRANSFER COEFFICIENTS FOR INSULATED WALLS}

Thomas K. Faison

(301) 921-3501

Building Physics Division

Sponsor: Department of Energy

With the advent of sharply higher energy and housing costs, the highly insulated prefabricated wall and the double-stud superinsulated wall have begun to appear on the housing market. Measurement of overall steady-state heat transmission coefficients have not been conducted for such highly insulated walls. The steady-state theory in ASHRAE's handbook cannot be used to predict the overall heat transmission coefficient for these walls because the theory does not adequately account for the significant effect of structural members. In this project, a series of steady-state tests will be carried out using the NBS Calibrated Hot Box (CHB) to experimentally measure heat transmission coefficients for the following two wa11 systems: A prefabricated insulated wa11 (nominal $\mathrm{R}-16$ ) and a double-stud superinsulated wall. Measured heat transmission coefficients will be compared with corresponding predicted values using both steady-state heat transfer theory and a finite-difference heat transfer model.

Project technical staff will meet with technical representatives of the National Association of Home Builders Research Foundation, the Manufactured Housing Institute, and DoE to arrive at wall prototypes that are representative of highly insulated walls for the housing market. A contractor familiar with these types of walls will be used to fabricate each of the wal1 systems. 


\section{EXPERIMENTAL HEAT TRANSFER FUNCTIONS}

Thomas K. Faison

(301) 921-3501

Building Physics Division

Sponsor: National Bureau of Standards

Until recently the transmission of heat through composite construction such as walls and roofs has been calculated on the basis of a steady-state model. As dynamic models have been developed, much of the data base has remained steadystate with adjustments made to compensate for dynamic response to climatic/ environmental changes. The Calibrated Hot Box provides CBT with unique capability to perform needed research to determine experimentally the relationships necessary for deriving the conduction transfer functions for composite wall assemblies. The Guarded-Hot Plate provides precision necessary to measure the effects of convective heat transfer in low-density fiber insulation. This work supports the CBT research on thermal performance of composite wall systems. These measurements will be made and the effect of convective transfer will be quantified with respect to density and aspect ratio (thickness to width) of insulation specimens. The data developed from these activities will benefit standards-generating organizations such as ASHRAE, ASTM and ANSI, and architects, engineers, specification writers, and building code officials. These findings will be of special use as a design aid and to estimate annual energy performance of buildings. 
Brian Rennex

(301) 921-3195

Building Physics Division

Sponsor: Department of Energy/Oak Ridge National Laboratory

Accuracy of measurement and quality control of the manufacturing process of thermal insulation are very important to the industry and consumer. The increased accuracy of thermal conductivity measurements makes it unnecessary for industry to compensate for uncertainty by overinsulating. The impact of having the NBS 1-meter Guarded Hot Plate (GHP) in service for thick insulation measurement, according to the industry and the U.S. Chamber of Commerce, is an annual savings to the consumer of $\$ 90$ million. The National Bureau of Standards has recently conducted an assessment of need for thermal reference materials that can be used as calibration specimens. Several materials show promise for expanding the ranges of temperature and thermal conductivity. The GHP was designed to be an accurate tool for conducting reseach and measuring the heat flux through thermal insulation and other building materials. The limitations of the apparatus and the effect of varying temperature and other control parameters over a finite range are important for future research on standard reference materials.

A detailed investigation of the thermal properties of Min-K, or another material will be undertaken. The thrust of this study will be to demonstrate the variability of heat flux relative to the control variables (temperature, ambient pressure, thickness).

The insulation industry needs standard reference materials that cover extended ranges of thermal conductivity and temperature. This research effort 
will document the operational limits of the NBS GHP. The results will allow accurate calibration of heat flow measurement apparatuses used in the industry's quality control, research and development efforts. Conservative allowances to account for large measurement uncertainties can be eliminated, allowing reductions in cost to industry and the consumer. 


\section{THERMAL RESISTANCE CALIBRATION STANDARD}

Brian G. Rennex

(301) 921-3195

Building Physics Division

Sponsor: Department of Energy

This project will explore the feasibility of developing a new calibration standard for thermal resistance measurement equipment such as guarded hot plates (ASTM C-177) and heat flow meters (ASTM C-518). At present only two materials are available from CBT for calibrating guarded hot plates and heat flow meters. One is a dense fiberglas board and the second is a low-desity fiberglas blanket. A need exists to supply the measurement community with calibration samples whose apparent thermal conductivity and thermal resistance is both higher and lower than those now available, either using materials that more nearly resemble those that will be measured in current production or using an entirely new calibration material approach; for example, plastics, insulating concretes, loose fill materials, or something like a variable wall spacing and wall thickness honeycomb type of material, whose thermal conductivity could be changed at will. Given success in this venture, a measurements laboratory desiring calibration would have the flexibility for calibrating their devices at or near the several ranges of values expected to be measured, thus improving the precision and acccuracy of their measurement system. Much money will be saved by the manufacturing industry if their production machines can be set more precisely to produce the $\mathrm{R}$-values required without excessive factors of safety. This, in turn, could lower prices to the consumer. 
Yai-May Chang

(301) 921-2330

Building Physics Division

Sponsor: U.S. Air Force

The objective of this project is to develop a guide for existing techniques that can be used to validate energy and cost savings achieved in the Air Force Energy Conservation Investment Program (ECIP) for projects in the Military Family Housing (MFH) and Military Construction Program (MCP).

Techniques considered for use in this guide will include spot metering, before and after metering, flip/flop equipment use, and regression analysis. Some additional applicable techniques include thermography, historical fuel use data, normalizing data by variable degree days, and measuring thermal conductance. The guide will identify all types of ECIP facility retrofits to be examined using these techniques (i.e., add insulation, replace lighting, reduce infiltration, add storm windows, add shading devices, furnace replacment, HVAC replacement, furnace derating, install heat pumps, install turbulators, waste heat recovery, night setback, etc.) and the proposed techniques to validate these retrofits. The guide will also specify which particular techniques are best suited to validate each type of retrofit. Data and calculations for each validation technique will also be provided to illustrate its use. 


\section{RESIDENTIAL INTERACTIVE TESTING PLAN}

Andrew K. Persily

(301) 921-2330

Building Physics Division

Sponsor: Department of Energy

This project will investigate the merit of fullscale interactive testing of residential buildings. The study is to specifically address the interaction of various parts of the building envelope and subsystems as they relate to the function of the building to achieve energy conservation. A multi-year DoE testing plan also will be developed. 
INDOOR AIR-POLLUTION CONCENTRATION MODEL

Preston E. McNall

(301) 921-3447

Building Physics Division

Sponsor: Environmental Protection Agency

A comprehensive analysis of pollution migration in buildings requires accurate simulation of all processes affecting pollutant concentration. These processes are infiltration, generation, dilution, reaction, removal, and exfiltration. CBT recently developed its comprehensive dynamic building simulation model, TARP. In addition to detailed thermal conduction and radiation calculations, TARP computes infiltration and interroom airflows by considering the flows through all openings (doors, cracks, etc.) and requires a mass balance in each room. The flows are a function of wind, stack effect, and forced ventilation. The TARP model automatically handles the infiltration, exfiltration, and interroom dilution aspects of the contaminant equation which are the most computationally complex part of the problem. It can serve as a framework for adding other components of the contaminant equation.

TARP would have to be expanded: first, detailed models would have to be developed for generation, reaction, and removal of various contaminants. Processes which are temperature-, humidity-, or pressure-dependent are using parameters already computed by TARP. Second, an air handling/ducting system model is needed to complete the simulation of forced interroom airflows and filtration devices. Third, the effects of interroom convection must be understood so that the simplified model can be developed. This area is primarily concerned with local air velocities, ventilation effectiveness, and removal of contaminants 
that have localized sources. Detailed models would be too time-consuming to include in long-term simulation. The resulting model will be widely used by building professionals, the Environmental Protection Agency, and the private sector. 


\section{PRESSED WOOD MODEL EVALUATIONS}

Samuel Silberstein

(301) $921-2758$

Building Physics Division

Sponsor: Consumer Product Safety Commission

This project will evaluate indoor air quality models including one developed by the National Academy of Sciences (NAS). The NAS model is being used by the Consumer Product Safety Commission (CPSC) to predict indoor formaldehyde concentrations resulting from pressed wood products in residences.

CBT constructed special measurement chambers to measure formaldehyde emission rates of full scale particleboard underlayment, plywood paneling, and medium-density fiberboard. CBT also constructed a prototype two-room house where several characterized specimens can be placed simultaneously to simulate real-life conditions. This equipment is located in one of CBT's environmental chambers, which has controlled constant temperature and humidity. The measurement chambers and prototype house are instrumented with an automated tracer-gas decay air exchange rate measurement system and an automated system for measuring formaldehyde concentrations.

From the measured emission rates of the pressed wood products and the air exchange rate of the house, formaldehyde concentration is predicted, using a mass-balance model, and compared with measured concentrations. These data, collected at "standard conditions" of $23^{\circ} \mathrm{C}$ and $50 \% \mathrm{RH}$, are then used with the NAS model to predict emission rates and concentrations at different combinations of temperature and RH. The temperature and $\mathrm{RH}$ of the environmental chamber are changed to predetermined conditions and the series of studies is repeated to compare the results to the predictions of the NAS model. The results of this study will enable CPSC to assess the validity of their models. 


\section{SPECIFICATION FOR HIGH-TECHNOLOGY BUILDINGS}

Richard Grot

(301) 921-3501

Building Physics Division

Sponsor: General Services Administration

The design and construction of modern high-technology buildings will place more stringent requirements on thermal performance, environmental components, air-conditioning contol, and ventilation systems. In an effort to achieve higher levels of efficiency and more precise operation, conflicts between design assumptions, construction integrity, and building operations can arise. A better understanding of the thermal, environmental, and operational characteristics of high-tech buildings is essential to avoid design errors that may result in a building unsuited to its tenants. At present, many buildings are now reported as environmentally "sick," unable to meet thermal comfort criteria and air quality standards.

Under this project, CBT is developing guideline specifications for the diagnostic evaluation of thermal and environmental performance of high-technology office buildings to be constructed by the General Services Administration (GSA). Specifications are in the Master Format, developed by the Construction Specifications Institute, as modified by GSA guidelines. The building specifications are being developed around existing diagnostic techniques developed by CBT for GSA on previous projects. However, these techniques will be modified to take advantage of the types of communication and control systems to be installed in high-technology office buildings. 


\section{UNDERGROUND HEAT DISTRIBUTION SYSTEMS}

Jin Fang

(301) 921-2278

Building Physics Division

Sponsor: Department of Defense Tri-Services Committee

Many underground heat distribution systems in military.installations are failing because ground water is corroding the conduit that covers the thermal insulation around the carrier pipe. Since it is extremely expensive to replace the entire underground system, it is desirable to have an accurate and easy-touse instrument that will detect only the segments of the system that have failed.

Last year, a simulated small-scale underground piping system consisting of two electrically heated pipes buried in dry sand showed that heat loss measurement by the thermal probe technique was in satisfactory agreement with the measured electrical power input to the simulated underground system. However, there is some discrepancy between the calculated and measured heat-loss values for tests involving wet sand. This may be caused by inhomogeneous settling of sand and moisture during the course of the test. A field test based on the thermal probe technique was performed for the system installed on the James Madison University campus in Harrisonburg, Virginia. The calculated depths and locations of the underground pipes agree reasonably well with the values found in architectural drawings. However, this field test showed that further refinement of drilling procedures as a part of the motorized auger is required for various hard soils encountered in field measurements and that the instrumentation used should be further developed for more automated calculation of the test results. 
The CBT measurement method is based on a simple heat transfer theory to calculate the heat-loss values from the earth temperature profile over the underground heat sources, provided that the thermal conductivity of the earth and the separation distance of the sources are known. Further validation of this instrumentation system and comparison of its performance with other measurement techniques are needed in actual installations. Eventually, the results of this project will assist in developing innovative underground heat distribution systems and encourage wider use of existing underground systems. 
ACOUSTICS 


\section{BUILDING ACOUSTICS TECHNOLOGY}

Simone L. Yaniv

(301) 921-3783

Building Physics Division

The state-of-the-art in building acoustics has not changed significantly in several decades and most acoustical parameters are still determined from sound pressure measurements using the diffuse sound field theory of sound propagation. Inherent in this model is the assumption that the sound pressure leve1--the parameter to which people respond--differs from sound power leve1-the rate at which acoustic energy is put into a room--by a constant amount in any room as long as the observation position is sufficiently removed from the source, and the room exhibits a very limit range of acoustical characteristics believed to be representative of residential and office spaces.

Unfortunately, diffuse sound field conditions are extremely difficult to achieve even in a specially constructed laboratory, and are seldom encountered in real buildings. Accordingly, determinations based upon far-field sound pressure measurements and the diffuse sound field theory yield results with large errors, and predictions of field performance from laboratory data that are chronically unreliable. Because building designers are generally cognizant of the inaccuracies associated with both acoustical data and predictions, they often react by costly overdesign. However, experience has shown that, despite the building industry's reliance on overdesign many buildings fail to meet acoustical specifications and require costiy corrective measures after the fact. 
The purpose of this multi-year project is to reexamine the relationship between sound power, sound pressure, sound absorption and decay in rooms, using data bases acquired by means of newly developed computer-based measurement tools that do not rely upon diffuse sound field theory. This work will allow for the development of significantly more reliable test methods and analytical tools for characterizing and predicting the acoustical performance of building spaces, systems, and materials. These analytical tools in turn will be used to develop computational algorithms for use in computer-aided design. 


\section{NOISE ISOLATION OF BUILDINGS EXPOSED TO AIRCRAFT NOISE}

S.L. Yaniv

(301) 921-3783

Building Physics Division

Sponsor: U.S. Department of Transportation

Federal Aviation Administration

The need to reduce the noise exposure experienced by individuals in the vicinity of airports led to the passage by Congress of the Aviation Safety and Noise Abatement Act (P.L. 96-193) of 1979. With the issuance of the Federal Aviation Regulations Part 150 "Airport Noise Compatibility Planning" a method was established for dealing with the noise impacts around airports nationwide. While any program involving airport noise compatibility planning involves many facets, one major aspect of such a program concerns the reduction of the noise exposure of individuals located in buildings impacted by airport noise. The technical data bases on the noise isolation of buildings from aircraft noise and on approaches for soundproofing buildings are scattered throughout the literature. These data are not readily available to noise compatibility projects sponsors, FAA airport field employees or other concerned people. A uniform method for quantitatively evaluating building noise isolation and obtaining cost estimates to achieve a degree of noise isolation improvement is required to insure that limited resources are used usefully, fairly, and consistently among all FAA regions.

The purpose of this research is to provide FAA airport field employees, local and state government staff, and other interested parties with a uniform methodology in a workbook format, using look-up tables, charts, graphs, and simplified calculation procedures to assess noise isolation. As required by FAA PART 150, the time-averaged A-weighted sound level will be used as the 
noise metric for the guidelines. These two requirements -- workbook format and A-weighted sound level measure -- establish the technical approach which will involve four tasks:

- data search and analysis to identify and select acceptable techniques and materials for mitigating aircraft noise intruding into buildings, to characterize aircraft noise sources to allow for estimating the A-weighted noise isolation with changes in the noise spectrum.

- identify major parameters such as source-building distance, angle.of incidence, percentage of envelope area for each building component and indoor room conditions required to quantify the building noise isolation and the sensitivity of the noise isolation to each parameter.

- develop cost estimates to implement the noise mitigation techniques previously identified.

- prepare an acoustic field booklet to obtain field data necessary to evaluate noise mitigation measures; and, guidelines describing how to synthesize the field data, evaluate and/or develop noise mitigation techniques including a series of technical appendices that describe the derivation and data used to develop the field booklet and the guidelines 


\section{AIRCRAFT NOISE ISOLATION: RESIDENTIAL BUILDINGS}

S.L. Yaniv

(301) 921-3783

Building Physics Division

Sponsor: U.S. Department of Defense Navy

Aircraft noise is a concern to the Federal Government, airport operators, state and local governments, the aircraft and building industries, and the public. There is a need for airports to meet transportation requirements and the continuing demand for urban expansion that protects airport neighbors from excessive noise. These conflicting needs are a continual source of annoyance and also a threat of conflict between airports and their neighbors that sometimes end in law suits.

The overall outdoor-to-indoor aircraft noise isolation characteristics of three types of residential building envelopes shall be estimated from noise insulation data on building envelope components and constructions, FAA and/or Navy take-off flight profiles, noise contour maps and spectral data of aircraft flyovers and their changes with distance. These estimates will be based on a model for predicting the aircraft noise reduction provided by residential and public building envelopes being developed by NBS for the Federal Aviation Administration. All estimates of building envelope noise isolation will be based upon existing information on the noise insulation of windows, doors, roofs, and walls using, to the fullest extent possible, accepted engineering practices, whenever available, and will not include testing of materials and/or building components, noise sources or sampling of environmental noise.

Noise isolation estimates will be confined to the envelope of three residential building types: conventional single detached housing, 
manufactured detached housing and multifamily dwellings such as townhouses, and/or garden apartments. Only construction practices common in Florida will be explored. For each construction type, the noise isolation will be estimated for at least two but no more than three types of architectural exterior finishes (e.g. wood, siding, brick veneer). Based on these analyses, modifications to current building practices in the state of Florida will be recommended to the Navy . 


\section{LIGHTING \\ RESEARCH}




\title{
DAYLIGHTING STUDIES
}

\author{
Stephen $\mathrm{J}$. Treado \\ (301) 921-2680 \\ Building Physics Division \\ Sponsors: National Bureau of Standards \\ Tri-Services Committee \\ Naval Civil Engineering Laboratory
}

The type, size, and configuration of window openings have a strong impact on building lighting, heating, and cooling loads. Daylight has been shown to have good potential for reducing lighting energy requirements; however, the effect of daylighting schemes on building heating and cooling energy requirements must also be considered. Since the luminous efficacy of solar radiation is typically two to three times that of electric light sources, the substitution of the proper levels of daylight for electric lighting can reduce heating and cooling loads substantially, while providing psychological and aesthetic benefits.

This year, the existing CBT luminance and illuminance distribution measurement capabilities wil be expanded to enable measurements on and about any task surface, for daylit and electric-lit spaces. Improved modeling and simulation procedures will be developed for incorporation into daylit calculation routines. The relationship between task visibility and daylighting design will be investigated. Daylight calculations also will be integrated with radiant exchange calculation procedures so that radiance (thermal) calculations include luminance distribution and interior illuminance calculations. 


\section{CEL-1 LIGHTING PROGRAM}

Steven J. Treado

(301) 921-2680

Building Physics Division

Sponsor: Naval Civil Engineering Laboratory

This project will support and maintain the CEL-1 lighting computer program and use it in conjunction with the BLAST program to evaluate various fenestration options for visual performance, building thermal and lighting loads, and building energy consumption.

Daylight utilization has long been recognized as an effective means of reducing the amount of energy required for interior building illumination. To determine the impact of daylighting on building energy, the effect of daylighting options on HVAC system 1oads, lighting loads, and visual performance must be evaluated in a comprehensive manner. As a result, a hybrid version of BLAST/ CEL-1 has been developed to allow the simulation of building energy performance, including lighting system performance and the effects of daylighting. To enable the development of design guidelines for effective fenestration use in buildings, the sensitivity of building energy usage to fenestration design must be evaluated as a function of other building parameters.

Results of this work are expected to decrease building energy requirements. 


\section{INTERACTION - LIGHTING AND HVAC SYSTEMS}

Stephen J. Treado

(301) 921-2680

Building Physics

Sponsor: Department of Energy

The objective of this research is to obtain the heat transfer characteristics of various lighting systems in typical room, to develop a database for detailed lighting heat balance calculations, to analyze the components of lighting heat transfer, and to evaluate the influence of wall and floor construction and HVAC design on lighting and cooling/heating loads.

ASHRAE studies indicate that electric energy consumption in commercial buildings constitutes as much as $50 \%$ of total building energy use. Since the early 1970's efforts have been made to reduce the lighting energy consumption without reducing its illumination performance, such as the development of high efficiency ballasts, high efficacy light tubes, and the use of daylighting.

This work will result in construction of a lighting test facility. A calorimetric chamber will be constructed within the existing large NBS environmental facility. This chamber will be constructed to emulate an office space with at least one wall capable of being exposed to the equivalent of exterior conditions.

This project is a combined, cooperative effort between the U.S. Department of Energy (DoE), the Electric Power Research Institute (ERPI), DubinBloom Associates and Ross \& Baruzzini, Inc. (DB-RB), and the National Bureau of Standards (NBS).

The thermal performance of lighting systems in actual room environments will be examined using a calorimetric chamber and the large CBT environmental chamber. The environmental chamber will be used to provide the "outdoor" condition for the calorimetric chamber, in which various lighting system and room configurations will be tested. 


\section{DEVELOPMENT OF ILLUMINATION MODEL}

Stephen J. Treado

(301) 921-2680

Building Physics Division

Sponsor: National Bureau of Standards

This project focuses on two aspects, luminance distribution and color rendering, as a function of electric lighting and daylighting systems and configurations. Prediction of the luminance distribution from luminaires and fenestration and consequent visibility of office tasks is needed for input to any design for interior space. In addition, prediction of the spectral reflectance as a function of light-source spectral-power distribution is needed to account for color within the space. Procedures are needed to allow the calculation of interior illumination conditions, and provide for displaying the resulting information in a graphic (two- or three-dimensional) format.

The FY85 effort will define the parameters for inclusion in a comprehensive illumination model and determining existing programs and subroutines. A simplified model will be developed, possibly using a variant of CEL.1 or a similar program. In future years, this model will be further developed and evaluated, and has the potential for wide use within the illumination and engineering community. 


\section{EFFECT OF CHROMATIC ADOPTION: COLOR RENDERING AND COLOR APPEARANCE}

Gerald L. Howett

(301) 921-2670

Building Physics Division

Sponsor: National Bureau of Standards

Only when the light source closely resembles daylight can the appearance of an object's reflection be predicted accurately from physically measured chromaticity. Because of the phenomenon of chromatic adaption (the eye's "discounting the color of the illuminant"), this coordination between appearance and chromaticity breaks down if the color of the light source departs significantly from that of daylight. A striking example of the shifts that can occur is the case of blue objects seen under high-pressure sodium light. At present, no formula is widely agreed-upon as being an accurate prediction of either the effect of chromatic adaption, or the appearance of colors seen under chromatic light sources.

The ultimate goal of a new color-appearance formula will require several lines of experimentation and computer modeling work, over a period of at least three to five years.

In FY85, three activities will be addressed: first, recent CBT studies of color appearance have depended on verbal reports that are only semi-quantitative. A more advanced approach is to match the appearance of samples under various light sources with the appearance of one sample from a large set of colors illuminated by a fixed reference source. Equipment to carry out such matching will be constructed by modifying an existing apparatus, and an experiment will be completed and reported. 
Second, the partially disassembled Maxmellian-view optical system will be restored to operational status and modified to provide for continuous scanning around. the spectrum locus and onto the purple line (where perceptually pure red lies). In FY86, an experiment using this equipment will determine constant-hue loci under adaptations to various light sources. The result will be a quantitative specification of what chromaticities a sample must have to appear, for example, to be a pure red hue, under adaptation to each of the light sources used.

Third, the most successful color-appearance formula to date was developed by Judd at NBS in 1939. It has predicted several sets of experimental data with moderate success. A start will be made on computer optimization to improve the agreement of the formula with these same data. In FY86, an improved version of the formula will be published. In FY87 and beyond, experiments will be done to confirm the predictions of the new formula with further fine-tunings carried out as needed. 


\title{
LIGHTING GEOMETRY AND CONTRAST MEASUREMENT
}

\author{
James A. Worthey \\ (301) 921-2177 \\ Building Physics Division \\ Sponsor: National Bureau of Standards
}

The purpose of this research is to develop a technique for measuring blackwhite contrasts in complex situations. Also CBT will develop a new technique for color-rendering calculations. There is an opportunity for rapid technical progress with respect to measurement of black-white contrasts and improvement of lighting geometry. It is generally understood that contrast is the stimulus for vision. No method exists, however, for measuring contrast in realistically complicated scenes. Since the eye probably makes some use of every edge, highlight and texture available to it, a realistic contrast meter should in some way "see" these features.

In the human eye, there are some $10^{7}$ receptors for daytime vision. From data gathered by the receptors, the visual system extracts object features such as edges and highlights, and them assembles a model of external reality, relying on a number of parallel methods of extracting three-dimensional information from the two-dimensional images on the two retinas. These methods of extracting information are a topic of current research, but in general terms they include "shape from shading," perspective, detection of observer motion through "streaming" of points in the retinal image, and stereopsis, which is the recovery of depth information from the disparities between the two retinal images. Extensive programming will be developed for manipulating images and for computing two-dimensional Fourier transform and a summary measure of contrast. 
In the area of color contrasts and lighting, as in the black-white area there is a need for research that better defines the systematic effects of a lighting change on color appearance. This effort involves developing computer programs for calculating color appearance as a function of light source spectral power distribution. In FY 85, computer programs will be developed to predict and quantify color contrasts as a function of illuminant. These will allow manipulation and graphing of light source spectral power distributions and object spectral reflectances.

The ultimate goal of the color-rendering work is a comprehensive new method to compute the main effects on object color of a change in lamps. This will provide explicit guidance to people designing building illumination systems. Proper control of lighting geometry and color rendering has great potential for providing good vision and reduced energy output. 
L. G. Porter

(301) 921-2660

Building Physics Division

Sponsor: Federal Aviation Administration

This project will evaluate the effectiveness of a CBT-designed color calibrator for measuring the relative luminance of colors used on a CRT display for a Radar Remote Weather Display System (RRWDS). It also will determine the effect of existing building lighting environments (in terms of illuminance, spectral power distribution [SPD], and location [geometry]) on the luminance and chromaticity characteristics of the RRWDS CRT display. CBT will recommend color tolerance limits for the color and luminance of each Weather Intensity Level (WIL), standard procedures for use of the color calibrator, guidelines for the RRWDS building lighting environment. Data on the performance of the color calibrator for calibrating video display units are urgently needed, particularly for different ambient illumination conditions. Changes in the illuminance and spectral composition of lighting systems may greatly alter the perceived luminance and chromaticity of the colors used to indicate weather intensity. 
SAFETY COLORS AND SIGNS IN WORKPLACES

Belinda L. Collins

(301) $921-3141$

Building Physics Division

Sponsor: Occupational Safety and Health Administration (OSHA)

The purpose of this research is to develop criteria for using safety colors and signs in workplaces. The emphasis is on developing criteria for using colors to code safety information, under energy-efficient (high intensity discharge) and mixed-1ight sources, and criteria for specifying the size of words and symbols as a function of viewing distance.

The Occupational Safety and Health Administration has begun revising its rules for the use of safety colors and signs in workplaces (Federal Register, Feb. 15, 1983). Although colors and signs are required for warning of workplace hazards and providing safety information, the research base for setting these requirements is inadequate. In particular, the use of High Intensity Discharge (HID) lights with poor color rendering may nullify color coding. As a result, CBT developed a set of experimental, retroreflective and fluorescent safety colors for use under these lights. The effectiveness of these colors is being experimentally validated under a variety of individual light sources, including some newer HID sources, as we11 as under mixtures of high and 1ow CRI sources.

A two-phase effort is planned. In the first, an 18-month phase, the use of colors to code information will be documented, along with existing sign/color/ symbol specifications. Two laboratory research projects will be conducted. In the second phase, methods for predicting the overall effectiveness of safety signs using words, symbols, and innovative colors will be developed, along 
with methods for predicting color appearance. Research findings will increase knowledge of the fundamental characteristics of color appearance and symbol visibility, while providing information upon which to base recommendations for safety color and sign use. 


\section{DISCRIMINABILITY FEATURES OF SECURE DOCUMENTS}

\section{Belinda L. Collins}

(301) 921-3141

Building Physics Division

Sponsor: Bureau of Engraving and Printing

The ultimate objective is to determine those features of existing and proposed secure documents (paper currency, postage stamps, drivers' licenses, social security cards, savings bonds, money orders, credit cards) that are most effective in deterring counterfeiting. The objective of this phase is to identify experimentally those features of counterfeit and genuine paper currency that may be useful in supporting identification of their counterfeit nature, under a variety of lighting conditions. The focus will be on the interactive effects of light-source parameters and currency features such as color and security devices.

This program is expected to result in redesign of the current system of paper currency, and ultimately to similar measures for other types of secure documents. Such measures are needed to reduce the threat posed by increasingly sophisticated counterfeiting operations. 


\title{
DESIGN CRITERIA IMPACTS OF OFFICE INFORMATION SYSTEMS
}

\author{
Arthur I. Rubin \\ (301) $921-3470$ \\ Building Physics Division \\ Sponsor: Office of Information Resource Management, \\ General Services Administration
}

The objective of this research is to develop design criteria for automated offices which satisfy the information management requirements of the General Services Administration and other federal agencies. This research involves an examination of current information systems and future trends as they are likely to be influenced by new technologies. Among the issues to be examined are the use of microcomputers computer securty and privacy, and the requirement for information resource guidelines.

During FY 85 work will consist of literature searches of information management, data and word processing technologies, security and privacy issues as they relate to organizational requirements, and existing guidelines for the development of information management systems. Surveys wil1 be conducted by NBS, GSA, and other federal agencies to determine the use of office automation hardware and software. An analysis of these data will provide information about the effectiveness of these systems in meeting organizational needs, and to identify potential problem areas that merit office design consideration.

This work will enhance the process of upgrading the current Information Systems activities of GSA, based on paper-based records, to the more effective use of electronic media. The office design and electronic data findings will be disseminated as guidelines for use throughout the Federal Government. 



\section{SYSTEMS AND CONTROLS LABORATORY}

George E. Kelly

(301) 921-2144

Building Equipment Division

Sponsor: National Bureau of Standards

The focus of this program will be developing mathematical models and measurement techniques for evaluating the performance of building systems and controls, encouraging energy conservation in buildings through improved control strategies and software, and developing guidelines for automated building management systems. This research effort will complement CBT's current DoEsponsored research program aimed at documenting the energy savings potential of the most commonly employed HVAC control strategies, developing algorithms for building control systems, evaluating the reliability of automated building management systems, and studying the application of sensors in energy monitoring and control systems.

This year's effort calls for the verification and refinement of HVACSIM using the NBS Administrative Building, development of the necessary supporting documentation for HVACSIM, and the production of a Users' Guide. A workshop on the integration of building services will be held in early 1985. Research aimed at evaluating the benefits of whole bulding control and various control algorithms using the Administration Building will begin in the summer of 1985. 


\section{ELECTRONIC BULLETIN BOARD}

George Kelly

(301) 921-2144

Building Equipment Division

Sponsor: Department of Energy

This project will create and operate an Electronic Bulletin Board that will support technology transfer by distributing information relating to CBT's recently developed building/HVAC/control systems simulation program, HVACSIM.

While copies of this program will probably be distibuted through NTIS, user support of such a program (i.e., answering questions, providing updates, assisting those with unique problems, etc.) is extremely important to its successful use by the private sector. The establishment of an electronic bulletin board will allow users with questions or problems to leave electronic messages. Answers to these questions or problems would then be formulated by Building Equipment Division personnel at their convenience and left on the bulletin board for all to read. This will ease technology transfer from the public sector to the private sector and also, hopefully, reduce the amount of time spent by CBT personnel answering the same questions repeated1y.

The software to operate an Electronic Bulletin Board will be purchased or leased and the bulletin board will be installed on CBT's minicomputer. It will be operated for a trial period to evaluate the usefulness to the private sector and the number of persons using it. It also will encourage the use of the new HVACSIM program by the private sector. In addition, it will provide valuable information on the role of such bulletin boards in technology transfer and information exchange in the future. 


\title{
ENERGY MONITORING AND CONTROL SYSTEM (EMCS) ALGORITHMS
}

\author{
William B. May \\ (301) 921-3839 \\ Building Equipment Division \\ Sponsor: U.S. Navy and Department of Energy
}

There are no standardized, nonproprietary EMCS algorithms avaliable for use by companies entering the building controls field. Many of these companies lack training and experience in HVAC systems, building controls, and algorithm development. As a result, the building owner or manager who purchases their system is often stuck with an EMC system that either doesn't work or only partially works.

To assure a minimum level of performance of EMC systems, CBT plans to develop public-domain algorithms for HVAC/building applications. Past work concentrated on the completion of algorithms for the control of building air handlers, including optimal start/stop, scheduled time of day stop/start, duty cycling, demand limiting, temperature reset, and economizer cycle. This year, the effort will involve the validation and refinement of these air handling algorithms, development of a model and computer program to emulate a building/ HVAC system controlled by an EMCS, and development of evaluation procedures for quantifying the energy savings expected from an EMCS prior to its purchase.

The development of public domain algorithms for EMC systems should greatly improve their performance, especially for systems made by small manufacturers, and lead to increased energy conservation in commercial buildings. Specifications of such algorithms will help to assure that future energy measurement and control systems provide at least this minimum of capability. 


\section{CONTROLS DYNAMIC MODELING}

Choel Park

(301) 921-3774

Building Equipment Division

Sponsor: U.S. Navy and Department of Energy

Current the building simulation programs; e.g., BLAST 2, DoE 2

do not account for HVAC control dynamics. As a result, there exists

little reliable data on the amount of energy waste in buildings due to control

dynamics and no information on how to design and operate building

control systems to optimize dynamic performance.

This research concentrates on developing simulation models to predict the dynamic, "minute-by-minute" performance of building systems. This work will

address the most common types of HVAC systems and will include research to develop simulation models for building equipment, HVAC components, controls and $z$ ones, and the simulation of the entire building/HVAC/control system. Work in FY84 concentrated on verifying and refining models of the various components found in building air handlers and developing a simple building she11 model and an interactive "front end" for a building/HVAC/control system simulation program called HVACSIM. Work in FY85 involves documenting these HVAC component and building shell models, and developing information that will encourage the use of this new program. 


\section{ENERGY ANALYSIS OF CONTROL STRATEGIES}

James Kao

(301) 921-3844

Building Equipment Division

Sponsor: Department of Energy

This study is needed to independently document the potential energy savings of different commonly used strategies. Last year, CBT used the computer program BLAST 2 to evaluate control strategies for a variety of HVAC systems in a large office building, a large retail store, a small office building, and a school in different regions of the country. Typical strategies studied were dry bulb economizer cycle, enthalpy economizer cycle, hot and cold deck temperature reset, zone control, floating space temperature, and scheduled setback. The results of these individual research studies will be combined and summarized in a report. This study will encourage energy conservation by providing design engineers and building owners with factual information on the benefits of the most commonly employed control strategies. It will also lay the groundwork for the future development of an advanced analysis tool for evaluating control dynamics and advanced control strategies. 


\section{NON-AZEOTROPIC REFRIGERANT MIXTURES \\ RESEARCH}


David A. Didion

(301) 921-2994

Building Equipment Division

Sponsor: National Bureau of Standards

The convective heat transfer coefficent is the single most important property for the design of heat exchangers. For those heat exchangers which have internal boiling or condensation coupled with forced convection (e.g., refrigerant systems, steam power systems), the complexity of flow conditions are such that coefficient values are normally completely empirically based. Since this study focuses on binary mixtures that are non-azeotropic (different boiling/condensation points), the problem is complicated even further. In single-component fluids it is typical to establish an empirically-based functional relationship between the convective heat transfer coefficient and the other transport properties (e.g., conductivity, visocity) for a given range of flow patterns and thermodynamic conditions. Once these relationships are established for categories of fluids, it is possible to predict the heat transfer coefficient based on the measurements of other transport properties that are significantly easier to make. In the area of non-azeotropic mixtures, virtually no such relationships among the transport properties exist.

The specific group of fluids that will be studied are fluorocarbons that are used or intended to be used as refrigerants. The apparent advantages of using non-azeotropic mixtures in refrigerant systems are improvement in efficiency, less environmental (ozone) impact, multi-level evaporators, and selflubricating working fluids. The evaluation of any of these possible advantages 
entails an overall performance evaluation of the refrigerant system, which in turn requires knowledge of the transport properties of the refrigerant. The heat transfer data and relationships that evolve from this study will be used by researchers in the refrigeration industry to quantify the advantages of binary mixtures in their future refrigeration systems design: Also, they wi11 provide CBT with a measurement facility that is equa11y applicable to the wide variety of binary mixtures found in chemica1 plants. 


\section{PERFORMANCE OF NON-AZEOTROPIC BINARY REFRIGERANTS IN RESIDENTIAL HEAT PUMPS}

David A. Didion

(301) 921-2994

Building Equipment Division

Sponsor: Oak Ridge National Laboratory

The objective of this research is to quantify the performance of the typical residential heat pump operating with a non-azeotropic binary refrigerant mixture as a working fluid. The purpose is twofold. First, CBT is currently modifying its heat pump performance simulation model to include non-azeotropic mixtures as the working fluid. This empirical study will be the hardware test verification needed to confirm the new cycle simulation. The second purpose is to measure the potential of these mixtures operating in a heat pump as typically designed today; that is, one designed to operate on a single-component refrigerant.

It is anticipated that the adoption of this concept in products being offered to the consumer could come about within three years. In certain climatic zones, this is estimated to offer an annual seasonal performance increase of four to five percent. The impact on cooling performance is currently being evaluated. 


\section{MODLEING THE PERFORMANCE OF NON-AZEOTROPIC REFRIGERANTS IN HEAT PUMPS}

David A. Didion

(301) 921-2994

Building Equipment Division

Sponsor: Electric Power Research Institute

The objective of this study is to develop a simulation model of a vaporcompression cycle operating with binary non-azeotropic refrigerant mixtures and to perform a parametric evaluation of the energy performance advantages of these mixtures for heat pumps. Conventional vapor-compression heat pumps use single component refrigerants or azeotropic mixtures (those which have a single boiling-condensing temperature-composition phase diagram) as their working fluid. The use of non-azeotropic mixtures as the working fluid appears to offer several advantages in the area of energy conservation. The major impact of this study will be the creation of the facility (the simulation mode1) to quantify the thermodynamic performance of these non-azeotropic mixtures in today's heat pumps and in future designs. The second impact will be the establishment of data on mixtures that may be used in other machinery systems. 


\section{TEST PROCEDURES \\ FOR \\ ENERGY APPLIANCES}


FURNACE, BOILER, AND HOUSEHOLD APPLIANCE TEST PROCEDURES

Esher R. Kweller

(301) 921-2627

Building Equipment Division

Sponsor: Department of Energy

This project will provide the industry, via DoE, an equitable testing and rating procedure for determining the seasonal energy performance of central residential furnaces, boilers, and household heating equipment. It also will assist DoE in this effort by conducting laboratory studies of furnaces, boilers, and household heaters and their associated equipment. The Energy Policy and Conservation Act (PL 94-163) and the National Energy Conservation Act (PL 95-619) require the Department of Energy to prescribe test procedures for various residential appliances, including furnaces, boilers, and household heating equipment. Test procedures for furnaces were published in the Federal Register in May 1978 (including test procedures for household heaters). Since then, DoE has updated and will continue to update the procedures to include new product designs coming on the market. On March 28, 1984, DoE published a comprehensive revision of the test procedures for furnaces, boilers, and household heaters, including new procedures for modulation-controlled equipment and unvented gas and kerosene heaters. During the course of this development, CBT has supported DoE in expanding or modifying the test procedures. This work will encourage energy conservation through the production of more efficient equipment for residential space heating. 
HOUSEHOLD APPLIANCE DATA UPDATE

Joseph Greenberg

(301) 921-3285

Building Equipment Division

Sponsor: Department of Energy

The Energy Policy and Conservation Act as amended by the National Energy Conservation Policy Act requires the development of test procedures, labeling rules, and energy efficiency standards for consumer appliances. Representative data, such as energy efficiency and energy use, are needed for these programs. These data have changed over time due to increases in energy prices, changes in consumer behavior, the availability of more efficient appliances, etc. In response to comments received during public reviews, this project will assure that tests, labeling rules, and standards are based on a consistent framework that uses the latest available data. These new values, if adopted and used, will give a truer picture of overall household appliance energy consumption and savings. This year, CBT will complete this work for room air-conditioners, central air-conditioners, furnaces, and water heaters. 


\title{
WATER HEATER TEST PROCEDURES
}

\author{
James E. Harris \\ (301) 921-2935 \\ Building Equipment Division \\ Sponsor: Department of Energy
}

The Energy Policy and Conservation Act (PL 94-193) has mandated that household appliances, including water heaters, be labeled for energy use using standardized testing methods. Thus, it is necessary to establish standard test procedures that allow the accurate determination of energy efficiency, are repeatable, and not burdensome to perform. The objectives of this project are to expand and/or modify the DoE water heater test procedures where required and to provide laboratory data, analyses, and recommendations related to the test procedures. In addition, CBT will participate in ASHRAE Standard Committee (SPC 115P) activity and will evaluate forthcoming proposed ASHRAE standard for testing the performance of heat pump water heaters. CBT also will participate in ASHRAE Standard Committee (SPC 124P, newly formed), "Method of Testing for Rating Indirect Water Heaters." CBT will evaluate the forthcoming proposed ASHRAE standard for indirect water heaters for applicability to labeling the annual cost of operation. 
SOLAR

EQUIPMENT 


\title{
CONTROL STRATEGIES TO IMPROVE SOLAR SYSTEMS PERFORMANCE
}

\author{
A. Hunter Fanney \\ (301) 921-3620 \\ Building Equipment Division \\ Sponsor: Department of Energy
}

In this project, CBT will explore ways in which the performance of solar systems that employ heat exchangers may be improved by using various control schemes. The schemes to be investigated control the flow rate through the storage tank side of the heat exchanger to minimize mixing within the storage tank and maximize the delivered thermal energy.

This reduction in flow rate will be studied in detail because it offers the advantage of increased performance without increasing the complexity and/or cost of the system. In the past, selection of the flow rates through both sides of the heat exchanger has been based on the desire to maximize collector efficiency. This approach has neglected the effect that higher flow rates tend to reduce thermal stratification within the storage tank, which increases the inlet temperature to the heat exchanger resulting in a decrease in the heat exchanger effectiveness.

The proposed work in FY85 consists of three major activities: first, measurement of typical heat-exchanger effectiveness for various flow rates and inlet-fluid temperature conditions; second, using the results of the activity above, detailed computer simulations of the complete system will evaluate the effect of flow rate on the performance of systems that use a heat exchanger; and third, heat exchanges will be added to two identical systems at the test facility. Extensive experimental comparisons will be made between the performance of the system using typical flow rates on the storage tank side of the heat exchanger and one which uses selected flow rates. 


\section{TEST METHODS AND EVALUATION PROCEDURES FOR CONTROLLERS USED IN ACTIVE SOLAR SYSTEMS}

Joseph Greenberg

(301) 921-3285

Building Equipment Division

Sponsor: Department of Energy

The field performance of many active solar systems has not been as good as expected. Data from instrumented sites indicate that approximately 40 percent of the monitored systems have performed at one-half, or less, of design expectations. Problem areas have included corrosion, leaks, poor design and installation, and poor reliability of control systems (including sensors). Controllers have been identified as the least reliable solar components in various studies of field problems.

CBT held a meeting with controller manufacturers in August 1983 to obtain recommendations for future research. One of the high-priority research areas identified was the development of test and evaluation procedures for controller hardware. In the future, the availability of the draft test methods will help establish a uniform basis for measuring and reporting the performance of these components. They also will provide a basis for users to establish needed performance levels and aid in improving the reliability of solar controllers. 


\title{
SECOND-LAW ANALYSIS OF SOLAR WATER HEATING SYSTEMS
}

\author{
A. Hunter Fanney \\ (301) 921-2538 \\ Building Equipment Division \\ Sponsor: Department of Energy
}

The second law of thermodynamics establishes the maximum possible efficiency for a system by revealing the amount of energy that is theoretically usable, called the available energy (exergy), in any process that works between the same temperature 1imits. A second-1aw analysis, therefore, provides the means to evaluate the effectiveness of a given system and can guide the optimization of system performance by identifying which inefficiencies are avoidable and which are exacted by nature.

Second-law analyses are becoming more common in solar engineering, but to date they have focused either on fundamentals such as the appropriate definition of a thermodynamic source temperature for solar radiation or on advanced technologies such as solar cooling. Little work has been done to analyze the performance of simple solar energy systems.

In this project, CBT will conduct second-law analyses of the performance of two solar domestic systems and their associated components. Based on these analyses, recommendations for system modifications to improve second-1aw efficiencies will be made. Estimates will be made of the improvement in overall system effectiveness that will result from recommended modifications. This research will guide the development of new optimization methodologies for solar energy systems. 


\section{THERMAL PERFORMANCE OF PASSIVE SOLAR APERTURES AND STORAGE COMPONENTS}

Michael E. McCabe

(301) 921-2308

Building Equipment Division

Sponsor: Department of Energy

The objective of this project are to identify and quantify the heat transfer mechanism that occur in building fenestration systems and storage components to develop standard methods for measuring thermal performance. At the present time, computer models of these components are often based on simplifying assumptions of one-dimensional heat flow and uniform and constant thermophysical properties. However, actual components used as apertures or storage elements often violate these assumptions, resulting in erroneous prediction of building energy performance. As an alternative to computer modeling, testing of actual components can provide realistic data upon which to improve the models and thereby obtain a good understanding of the dynamic heat transfer mechanisms.

Indoor test apparatus are convenient to use but are not yet able to accurately simulate the environmental conditions required to characterize the thermal and optical performance of advance components. This problem can be overcome by testing in the natural outdoor environment. Outdoor test apparatus are less convenient to use but provide the most realistic thermal environment for testing components. The combination of outdoor and indoor testing of components, the development of computer models based on first priciples, and. validation of these models using the experimental data will provide the basis for quantifying dynamic heat transfer mechanisms in components. Outdoor test data obtained in the CBT calorimeter for a number of fenestration systems and 
collector-storage walls provide a data base for continued study of dynamic heat transfer mechanisms. These data can also be used to improve the realism of the indoor test methods and lead to the development of standards-testing procedures. Since improvements in the performance of components and systems is one of the long-term goals of the DoE program, it is essential that appropriate techniques be developed to measure the thermal performance of advanced components. 
THERMAL PERFORMANCE OF EXPERIMENTAL PASSIVE SOLAR SYSTEMS

Bal M. Mahajan

(301) 921-3294

Building Equipment Division

Sponsor: Department of Energy

This project will measure zone-to-zone air flow in various passive solar systems under different experimental conditions to support the development and validation of interzonal heat-transfer algorithms.

Experiments will be conducted at the CBT test facility with an open passageway between the Trombe wall cell and control cell, and between the control cell and direct gain cell. The velocities of air flowing from zone to zone will be measured under different test conditions: cell air temperature free floating and fans on, and cell air temperature free floating and fans off. The data will be examined for the effects of temperature, stratification, and forced air movement within each cell. The effects of the remaining variables on interzonal air flow will be studied in FY86. 


\section{EXPERIMENTAL PASSIVE SOLAR SYSTEMS}

Joseph Greenberg

(301) 921-3285

Building Equipment Divison

Sponsor: Department of Energy

The DOE Passive Solar Experimental Systems Program was established to collect, analyze, and archive detailed laboratory, test-ce11, and building performance data of high quality. These data are to be used for the validation of whole-building energy-calculation methods and component models and for the development of new algorithms that characterize the behavior of innovative components, systems, and subsystems in buildings. At present, the NBS Passive Test Building is one of nine test facilities or buildings in the experimental systems network of five passive heating facilities and four passive cooling facilities. In addition, other data are being taken at several other facilities, both within and outside of DoE sponsorship. The data needs of the users and the tests conducted by the test facilities are periodically reviewed by a Coordinating Committee and others.

In FY84, CBT in collaboration with the Coordinating Committee prepared a draft multi-year plan for the Experimental Systems Research Program. In FY85, this multi-year plan will be completed and published. Based on FY85 activities, CBT will provide DoE with recommendations for revising the multi-year plan. 


\section{RADIATIVE HEAT-TRANSFER MODELING}

Michael E. McCabe

(301) 921-2308

Building Physics Division

Sponsor: National Bureau of Standards

The objectives of this project are to develop a computer code that models the admission and subsequent absorption of the radiant flux from sun and sky in partially transparent building spaces.

A matrix formulation of solar radiative heat transfer in partially transparent enclosures has been developed. The enclosure model predicts the instantaneous rate of solar energy absorption at each surface of an enclosure into which beam and diffuse solar radiant energy are transmitted. The computer code SUNFLX has been developed to model ideal transmitting surfaces and surfaces that reflect energy in a diffuse manner. Algorithms to compute diffuse radiative view factors and beam radiative blockage factors based on configuration geometry have been obtained and will be incorporated into the code. Tabular values of the optical properties of typical glazing systems will be provided with the option of user-provided optical characteristics.

The significance of the code with respect to building energy balances in a simple geometric enclosure will be determined by comparing predicted results with buiding energy analysis codes such as TARP/BLAST, DOE-2, etc., and with solar building codes such as TRNSYS, DEROB, and PASOLE. Detailed parametric studies will be performed to determine the accuracy of the existing codes and therefore the domain of applicability of SUNFLX. 
Generalization of the code to include both nonideal radiant transmisison through glazing systems and mixed specular and diffuse reflecting characteristics of surfaces will be investigated. The computer code will also be applied in the prediction of daylighting distribution in complex geometric enclosures. 

SOLID-STATE DEHYDRATION

Leslie Struble

(301) 921-2635

Building Materials Division

Sponsor: U.S. Department of Energy

The objective of this research is to assess the potential of a hydrated calcium aluminate sulfate salt (Candlot's salt or ettringite) and related salts as phase change materials for passive solar energy storage. Solar energy storage may utilize latent heat stored and released by a material during a phase change. This phase change often, though not necessarily, involves melting and freezing. To be used for energy storage, a phase change must involve a high change in enthalpy (e.g. $100 \mathrm{cal} / \mathrm{g})$ and must be fully reversible. For passive energy storage, the phase change must occur at temperatures below approximately $40^{\circ} \mathrm{C}$. Other considerations are that the material be safe, nonflammable and nontoxic. Dehydration and rehydration of Candlot's salt, appears to offer potential for this application.

The experimental approach is to develop procedures to synthesize Candlot's salt and a number of phases of the same type, involving substitution of various constituents. These phases will be characterized and their thermal properties measured, particularly dehydration temperatures and enthalpy changes during dehydration. Reversibility of the dehydration will be determined for each material. 


\section{INORGANIC COMPOUNDS FOR PASSIVE SOLAR ENERGY STORAGE - HIGH SPECIFIC HEAT MATERIALS}

Leslie Struble

(301) 921-2635

Building Materials Division

Sponsor: U.S. Department of Energy

The objective of this research is to assess the potential of a hydrated calcium aluminate sulfate salt (Friedel salt) and related salts for passive solar energy storage. Solar energy storage utilizes either latent heat (change in enthalpy associated with a phase change) or sensible heat, the heat stored or released when the temperature is raised or lowered (specific heat). The objective in developing a system for sensible heat storage is to find a high specific-heat material, which is stable under the operating conditions of the system. Other considerations are that the material be safe, nonflammable and nontoxic. Hydrated calcium aluminate sulfate salts appear to offer potential for this application.

The experimental approach is to develop procedures to synthesize Friedel salt and a number of phases of the same type, involving substitution of various constituents. These phases will be characterized and their thermal properties measured, particularly specific heat. 


\section{TECHNICAL PROBLEM ASSESSMENT}

Robert D. Dikkers

(301) 921-3285

Building Equipment Division

Sponsor: Department of Energy

This project will provide technical support and assistance to the Solar in Federal Buildings Program established under the Energy Policy and Conservation Act and the National Energy Conservation Policy Act. The Solar in Federal Buildings Program (SFBP) was established to show Federal confidence in and focus public attention on proven applications of solar heating and solar heating and cooling technology that can be used in the private sector. SFBP rules published in the October 19, 1979, Federal Register referenced performance criteria for solar heating and cooling systems in commercial buildings (NBSIR 76-1187) prepared by CBT. As of June 1984, 731 SFBP projects were still active.

During prior years (FY80-83), CBT staff have provided recommendations concerning data collection and evaluation activities that should be carried out under the SFBP. In FY84, a CBT staff member was selected to serve as a member of the SFBP Editorial Review Board. The objective of this board is to provide recommendations concerning the scope and type of technical reports and information to be prepared and disseminated under the SFBP. During FY85, NBS staff will continue to participate in the SFBP Editorial Review Board and to provide other technical assistance to the SFBP as may be requested.

The impact of this program will be widespread since data collected on the design, construction, and performance of solar heating and cooling systems in the SFBP will provide the solar community with valuable information for improving solar equipment. 


\section{TECHNICAL COMMITTEE ASSISTANCE}

\section{Robert D. Dikkers}

(301) 921-3285

Building Equipment Division

Sponsor: Department of Energy

It is expected that solar standards, being developed by ASHRAE, ASTM, and other organizations, will provide industry, government officials, designers, and consumers with a uniform basis for the evaluation, development and selection of solar energy materials, components, and systems. CBT will actively participate in various committees of organizations (e.g., ASHRAE, ASTM, ISO, ANSI) now engaged in standards development and planning activities. Where appropriate, CBT staff will provide research data and draft standards to assist these committees in the preparation of voluntary consensus standards. The nationally accepted voluntary consensus standards for solar materials, components, and systems will contribute to developing a viable solar industry. 
CONSULTING AND ADVISORY SERVICES: ACTIVE SOLAR HEATING AND COOLING

Robert D. Dikkers

(301) 921-3285

Building Equipment Division

Sponsor: Department of Energy

Under this task, CBT will provide consulting and advisory services to technically support DoE (Active Heating and Cooling Division). These services include the following activities: active participation in conferences sponsored by DoE, SERI, ASHRAE, and other organizations to discuss performance criteria, standards, and various research activities; meetings with representatives of other government agencies (Federal and/or State) and foreign governments at the request of DoE to discuss CBT solar energy program activities; active participation in DoE planning and program review meetings; and review and evaluation of requests for proposals, contractor reports, program planning documents, and other program activities. 


\section{INTERNATIONAL ENERGY AGENCY SOLAR PROGRAM SUPPORT}

\section{A. Hunter Fanney}

(301) 921-2538

Building Equipment Division

Sponsor: Department of Energy

This project will enhance the U.S. solar research program by participation in Task III of the International Energy Agency Solar Heating and Cooling Research Program. The intent of the first subtask under this project is to establish a reliable, adequate methodology for relating the instantaneous performance of a solar collector as determined in collector testing to the day-long performance of that collector in a system. The current testing procedure eliminates or minimizes the very real effects of wind, sky temperature, distributions of direct and diffuse solar radiation, and nonsteady-state operation. These effects must be taken into account in determining collector performance in a system.

The purpose of the second subtask is to establish the quantitative basis for evaluating candidate materials for solar collectors. The current test methods are based on qualitative indicators that cannot be related easily to real performance. Most can give a relative ranking of performance but none indicates at what rank the performance becomes unacceptable for the intended application. This situation generally results in over-specification of materials by designers, with an attendent increase in cost.

The purpose of the third subtask is to establish a method where the longterm performance of a solar domestic hot water system can be adequately predicted using he results of short-term tests. The long-term performance of a system 
is the only reliable indicator of its effectiveness to the user. The methodology must include transformation of test results from arbitrary conditions of test to the real conditions at the installation site. In addition, the methodology should allow for component substitutions to be made without requiring a complete retest of the modified system. The test procedures will result in a consistent terminology and universally accepted data reporting on an international basis. 
PLUMBING

RESEARCH 


\title{
HYDRAULIC LOAD LIMITS IN DRAINS
}

\author{
Lawrence S. Galowin \\ (301) 921-3293 \\ Building Equipment Division \\ Sponsor: Tri-Services
}

This project will determine hydraulic drain load-carrying capacities for building plumbing drainage systems by applying the Plumbing Load Drainage Design multi-network computer program. The program will be applied to representative military buildings to provide new guidelines for facility and base engineers.

This new procedure takes into account vertical stack annular flow and attenuation in horizontal drains dependent upon pipe parameters, base flows, and surge waves. Initial loading conditions for any sequential, simultaneous, random, and discrete fixture discharges into the system can be prescribed. Prior procedures and design calculations, based upon drainage fixture units, cannot account for the time-varying hydraulic discharge profiles from fixtures and yield results that underestimate system hydraulic capcacities.

The results of this work will provide revisions for hydraulic load limits during the site planning phase in new installations or for existing drainage pipe systems where changed functions and occupancy usages occur. Dissemination of the results will advance the applications for computer-aided design methods in the plumbing field and contribute to the ASPE Data Book for Plumbing Design. 


\section{LOAD MODELING FOR MULTISTORY DRAINAGE SYSTEMS}

Lawrence S. Galowin

(301) 921-3293

Building Physics Division

Sponsor: National Bureau of Standards

This project will expand the existing flow network analysis program for building drainage systems by the introduction of top-entry branch-junction boundary conditions and iterative recalculation procedures so the program is more useful as a design tool. The results will contribute to introduction of the new computer-based design methods for building plumbing drainage systems. Traditional plumbing code requirements and design practices for drains are based upon conservative tabulations of permissible pipe size derived from empirical factors for the hydraulic capacity. Dissemination of CBT reports and articles for inclusion in the American Society of Plumbing Engineers Data Book "Fundamentals of Plumbing Design," can expand the opportunity for computer-aided design in the plumbing field. 


\section{RESIDENCE TIMES IN FLOW SEPARATION - WATER MAINS}

Lawrence S. Galowin

(301) 921-3293

Building Equipment Division

Sponsor: U.S. Environmental Protection Agency

This research has two objectives. The first is to evaluate flow separation conditions and eddy formations at cavities and obstacles at pipe walls in water distribution mains. The second is to develop a residence time flow model for recirculation in cavities; experimentally determined surface ramp contours of growth from deposits at wall obstacles.

Potential degradation of potable water quality in water mains was related to pipe wall encrustations by the Environmental Protection Agency. The hydraulic phenomena governs the local conditions at and adjacent to the wall where corrosion, chemical and biofilm adhesion occur. The transport and deposition of particulates, chemicals, and nutrient retention for bioorganisms were identified as dependent on residence times.

CBT will develop flow separation and eddy formation modeling to simulate flow conditions at wall obstacles. Representative separated regions at wall obstacles and stagnation conditions at imperfectly aligned pipe sections, gasketed joints, fittings and valves, roughness sites and corrosion/encrustation sites will be considered in the modeling. Computer programs that account for viscosity diffusion will also be assessed. Comparisons with limited published experimental data profiles will be made. The findings will provide a preliminary model for EPA use as a technique for predicting local pipe conditions for distributed potable water quality. 


\section{QUALITY OF BUILDING MATERIALS}


Jonathan W. Martin

(301) 921-3208

Building Materials Division

Sponsor: National Bureau of Standards

Reliable prediction of service life is needed to aid the selection and use of polymeric building materials. But major technical barriers to the development of predictive models arise from the complexity of the degradation processes, particularly the synergistic effects of ultraviolet radiation, temperature, moisture, and other factors. Currently, predictive models and accelerated tests do not account for this synergism. The thrust of this research is to develop stochastic models incorporating synergistic degradation effects. These models will be validated against laboratory and outdoor test data.

Prior research has led to the development of a stochastic model as a function of two of the above degradation factors (ultraviolet irradiance and temperature) and two degradation processes (thermal degradation and photo degradation) using polymethylmethacrylate (PMMA) as a model material. The model is fundamentally based in that the parameters of the model are in terms of material degradation processes. Parts of the model have already been verified against 25 published data sets. The agreement between the model's prediction, empirical data, and the fundamental mechanisms of chemical degradation, are very good. The full model is currently being validated against laboratory data and validation will be completed in FY85.

This research will extend the model to include moisture and to mathematically clarify the causes of thermal degradation. The work will be done in collaboration 
with the staff of the NBS Polymers Division. PMMA specimens will be exposed to several relative-humidity levels, keeping irradiance and temperatures constant. The level of moisture in each specimen will be measured using a Fourier transform infrared measurement technique. Degradation of the materials will be measured using gel-permeation chromatography. In the mathematical modeling phase of the research, extensions will be made to the current stochastic mode1. Degradation will be modeled in terms of the chemical/physical changes occurring within the material. 


\section{ENVIRONMENTAL DEGRADATION OF POLYMERIC COVER MATERIALS FOR SOLAR COLLECTORS}

David Waksman

(301) $921-3114$

Building Materials Division

Sponsor: Department of Energy

Virtually all of the durability testing that has been performed to date on polymeric materials for solar energy applications has concentrated on their degradation when exposed to elevated temperature and ultraviolet radiation. Little emphasis has been placed on degradation caused by moisture or by the combined effects of moisture, temperature, and solar radiation.

Under this project, moisture-related degradation that has occurred in cover materials exposed in previous CBT programs will be characterized. Carefully controlled exposure tests will be conducted for representative materials to determine their degradation mechanisms and degradation rates and to establish a basis for predicting the useful service lives of these materials. Research will be performed to develop the data to a stochastic mathematical model for predicting the synergistic degradation effects of moisture, ultraviolet.radiation, and temperature. The model will also be validated for one or more additional materials to demonstrate its broad applicability.

Knowledge gained in this research will assist industry in formulating polymeric materials for solar applications and the evaluation procedures developed, in cooperation with organizations such as ASTM, will aid the selection and use of polymeric materials. The development of validated mathematical models also will significantly advance the current state-of-the-art in predicting the rates of degradation of materials which will, in turn, aid in providing evaluation tools for selecting and using such polymers. 


\section{DEPENDENCE OF MECHANICAL PROPERTIES ON MICROSTRUCTURAL CHANGES IN COVER PLATE MATERIALS}

David Waksman

(301) 921-3114

Building Materials Division

Sponsor: Department of Energy

Primary emphasis in developing ASTM procedures for evaluating solar materials degradation has been placed on their engineering properties, i.e., integrated transmittance and absorptance, emittance and tensile strength. Little emphasis has been placed on the use of changes in the primary microstructural properties of these materials for early detection of changes in the engineering properties which are, in general, less sensitive indicators of materials degradation. An understanding of primary degradation mechanisms and their influence on engineering properties is essential for the formulation of improved products by industry and early detection of materials degradation. CBT will determine the relationships that exist between micro and macro-level changes in the mechanical properties of polymeric materials. Measurements will be made of changes in the chemical, i.e., molecular weight, and physical, i.e., microstructural (microcracking), properties of materials exposed in the NBS cover plate and collector reliability/durability programs. The relationships between changes in these properties and the macroscopic (mechanical) properties of these materials will be determined. 


\section{DEVELOPMENT OF TESTS FOR PREDICTING ADHESIVE BOND DURABILITY}

Jonathan W. Martin

(301) 921-3208

Building Materials Division

Sponsor: U.S. Army, NARADCOM

All branches of the military use lightweight, air transportable, rigid structures which serve as combination shipping containers and shelters for many types of tactical and life-support services. The use of these shelters has increased rapidly in recent years and life-cycle costs have become a major consideration. The shelters are fabricated from either paper honeycomb core or foam plastic sandwich panels. While honeycomb panels have several potential advantages, field experience has shown many problems. De-bonding of panel components, stemming from poor adhesive performance, is a frequently observed problem. To address poor adhesive performance, a need exists for developing improved accelerated tests and probabilistic based mathematical models to aid in predicting service life.

CBT will expose honeycomb sandwich panels to a cyclic temperature environment at 95 percent relative humidity. The panels will be monitored for delaminations as a function of exposure time. The time at which delaminations are detected is the service life for the panel. The service life for panels exposed to the same exposure conditions will be used in determining a suitable theoretical life distribution. The parameters of the life distribution will be used in determining the time-tranformation function relating time to failure and thermal stress. This transformation function will be useful in predicting service life under varying environmental stresses. The development of improved accelerated tests and probabilistic based models will provide the technical bases for standards for adhesives 
used in honeycomb sandwich panels. These standards will contribute to the technical basis for the expansion of the military shelter program which is to take place in the $1980^{\prime}$ s under the newly-formed inter-service committee designated the Joint Committee on Tactical Shelters. The benefits will be improved performance of military shelters and spinoff benefits for civilian shelters. 


\section{NONDESTRUCTIVE EARLY DETECTION OF CORROSION AND DELAMINATION UNDER PROTECTIVE COATINGS USING THE THERMAL WAVE METHOD}

Tinh Nguyen

(301) 921-3208

Building Materials Division

Sponsor: National Bureau of Standards

United States corrosion related problems are estimated to cost more than 100 billion dollars annually. The use of coatings is one of the most effective, economic and widely-used means to prolong the service life of corrosion-prone substrate materials used in buildings and infrastructures. Current methods to detect and assess corrosion of steel under protective coatings, and delamination at the metal/coating interface involve visibly observing or destructively peeling off the film. Another method, thermography, was recently developed at CBT for the non-destructive detection of corrosion and blisters under protective coatings. All of these methods suffer a major disadvantage: the detection is only possible after the materials have been severely damaged. Thus, one of the objectives in research on service life prediction of coatings on steel is to develop a nondestructive method to detect very early corrosion and delamination under pigmented coatings. A recently developed method, thermal-wave imaging, has been applied in the semiconductor industry to detect and image small subsurface defects, microcracks and dopant regions. It appears from these results and from our preliminary work that the method has the potential for use in the early detection of corrosion and delamination under coating films. Thermal wave detection and imaging are dependent on material properties such as specific heat, thermal conductivity and density, and the modulation frequency of the electron beam used.

The objective of this research is to investigate the depth of penetration of thermal waves in coatings for detection of corrosion of steel protected by 
these coatings. To address this question, corroded steel specimens will be coated at incremental thicknesses. Modulation frequencies and phase shifts will be varied until the corrosion is imaged.

Development of a nondestructive method for early detection of corrosion and changes at the organic coating/metal interface will permit quick assessment of coating performance in many different environments and rapid screening of experimental coatings and corrosion inhibitors. This could lead to better understanding of the degradation mechanisms, improved coatings and coating systems, and improved accelerated testing methods; also, it could ultimately reduce testing time and cost. 


\section{ASSESSMENT OF NONDESTRUCTIVE EVALUATION METHODS APPLICABLE TO CONSTRUCTION}

James R. Clifton

(301) 921-3458

Building Materials Division

Sponsor: Naval Civil Engineering Laboratory (NCEL)

Nondestructive evaluation (NDE) methods offer significant advantages over traditional methods for determining the properties of construction materials, especially in the making of in-situ measurements of materials. CBT completed a study on NDE methods, "In-Place Nondestructive Evaluation Methods for Quality Assurance of Building Materials," in 1982. Since then, advances in the state-of-the-art of some NDE methods have taken place. The purpose of the project is to update the assessment and to identify emerging and advanced NDE methods.

The research will consist of four tasks. The first is to identify and evaluate current Navy practices relative to the use of NDE methods in the construction and service cycle of buildings and other structures. The second is to determine the state-of-the-art of the use of NDE methods in the construction industry. In the third, emerging NDE methods that have application to naval diagnostic needs will be identified. Also, promising advanced NDE methods which require further research and development before they are ready for routine use will be identified. Needed research in the area of NDE methods for naval construction applications will be addressed in the fourth task. 


\section{ORGANIC COATINGS}

Dr. Mary McKnight

(301) 921-2635

Building Materials Division

Sponsor: Tri-Services Materials Committee

The annual cost associated with protective coatings in the U.S. for buildings and structures is estimated to exceed 8 billion dollars. If the most effective criteria for the selection, specification, and use of protective coatings were available, it is estimated that as much as 25 percent of these expenditures could be saved. An essential element of selection and use criteria for protective coatings is service life. But currently available methods for predicting service life based upon short-term tests do not adequately meet the need for data to aid selection, specification, and use.

The objective of this research is to develop improved test and evaluation methods for predicting service life of protective coatings under in-service use conditions to aid in selecting and using protective coatings. CBT will develop improved test and evaluation methods to aid service life prediction. The thrust will focus on 1) identifying and modeling the mechanisms of degradation and 2) identifying properties and characteristics which are effective indicators of degradation and performance. The scope of the research is limited to protective coatings for steel.

In FY 84, the project focused on refining mathematical models for service life prediction for coatings on steel, evaluating current test methods used to characterize performance of waterborne emulsions and developing improved test methods, and transferring state-of-the-art 
information on selection and use of coatings by initiating revision of the Paint and Protective Coating Manual. The waterborne emulsion work will support development of an ASTM standard specification for interior flat latex wall paints. In FY 85 , research to better characterize initial properties of the coating system will be initiated and support for developing an ASTM standard specification for interior waterborne paints. 
Mary McKnight

(301) 921-2635

Building Materials Division

Sponsor: Naval Civil Engineering Laboratory (NCEL)

The need for improved short-term tests to aid quantitative service-life prediction of coating systems is well documented. A primary weakness of current short-term or accelerated tests is the procedure used to characterize the state of deterioration (level of performance) of the coating system. Currently, most evaluations of performance of coating systems are made using visual standards. These standards are quite qualitative and are not suitable for evaluating systems in the early stages of deterioration. If the need for improved service life prediction methods is to be met, quantitative and sensitive methods for characterizing the performance of coating systems must be developed and implemented. This research is directed to improvement of characterization procedures for performance of coating systems.

The research is divided into two parts. The first builds upon preliminary research and will use infrared thermography for quantitative characterization of degraded coating systems. The second is a literature review of other non-electrical characterization procedures. For the first part, the evaluation of coated laboratory steel panels for corrosion and blistering using infrared thermography will be computerized. Computer software has been developed to digitize the image. The number of the deteriorated areas and the total area of deterioration will be quantitatively determined, accumulated over time and stored in a computer. The data will be retrieved and analyzed as desired. The second part consists of a literature review 
and contacts with research laboratories to identify additional nonelectrical state-of-the-art methods used to characterize and measure deterioration of coating systems. These methods will be evaluated for practicality for quantitative determination of the degraded state of a coating system and detection of early stages of deterioration. Research needs for the development of potentially attractive methods will be identified. 


\section{COATING MAINTENANCE OF FACTORY COATED METAL SIDING AND ROOFS}

Mary E. McKnight

(301) 921-2635

Building Materials Division

Sponsor: Air Force Engineering and Services Center

The Air Force has constructed many facilities with sheet metal siding or roofing. Many of these buildings are more than 20 years old. Periodic coating maintenance is required to maintain these facilities. Current directives and guidance do not adequately address problems associated with maintenance of these buildings. As a result, Air Force bases are using a mixture of coating systems that 1) often fail prematurely, 2) inadequately protect the facility, or 3) are excessively difficult to recoat.

CBT will develop technology to improve preliminary guidelines for maintaining metal siding and roofing. This will be accomplished by producing laboratory and field test methods. Laboratory and field test methods will be selected and candidate maintenance coating systems and application methods will be tested and evaluated. Surface preparation techniques will be evaluated taking into consideration the type and condition of the substrate. Using the initial results of the laboratory and field tests and information from condition assessment procedures, interim criteria will be prepared for recoating metal siding and roofing. This work will be published as a pamphlet or short document and distributed to Air Force bases. 


\section{DEGRADATION OF ORGANIC PROTECTIVE COATINGS}

Mary E. McKnight

(301) 921-2635

Building Materials Division

Sponsor: National Bureau of Standards

This project focuses on the identification of mechanisms leading to blister formation and corrosion. It aims at developing improved methods for characterizing coating reactions and properties that control degradation at the steel/coating interface. Previous research has led to preliminary mathematical models for predicting the growth of blisters and a method, based upon infrared thermography, for detecting degradation beneath coatings.

This year, research on interfacial degradation mechanisms will use Fourier Transform Infrared Spectroscopy (FTIR) to study the molecular changes at the steel/organic coating interface. The information obtained will be used for elucidating the mechanisms of coating degradation and for identifying the factors controlling degradation. The proposed research will study the coatingsteel interactions before and after exposure to corrosive environments and relate these to the protective characteristics of coatings.

Several types of organic coatings will be put onto steel surfaces. FTIR will be used to study steel/coating interactions at the interface. The coated specimen will then be exposed to environmental conditions simulating in-service exposure. The specimens will be reexamined using both FTIR and optical microscopies. Molecular behavior will be correlated with rate of degradation. 


\author{
Mary E. McKnight \\ (301) 921-2635 \\ Building Equipment Division \\ Sponsor: Naval Facilities Engineering Command \\ Northern Division
}

The Tri-Service Paints and Protective Coatings Manual (M0110, AF85-3 or TM5-618) is the prime document used by engineering commands to specify coatings systems for facilities maintenance. The document provides base engineers with general information on coating chemistry, surface preparation and application procedures, inspection, failure analysis and safety. The last revision was completed about five years ago. Since new coatings are available, the manual's revision is necessary.

Information from technical literature and government and industry coating experts will be used to update the manual. Techniques to increase the ease of information transfer will be investigated and used as appropriate. Chapters on field inspection instruments and procedures and safety will be written. When revisions are completed, the Navy will publish it and distribute to military bases. The improved coating systems specification will result in improved service life and lower maintenance costs for military facilities. 
TRI-SERVICES TECHNICAL AND SCIENTIFIC SUPPORT

Robert G. Mathey

(301) 921-2629

Building Materials Division

Sponsor: Tri-Services Committee

The military servies are facing a wide range of building-related problems.

In response, this project provides technical and scientific support and

consultative services on building materials and systems as required by the

Tri-Services Building Materials Investigational Program Committee. The work

includes laboratory tests and field investigations for solving building problems.

Recommendations are made on the selection of materials and systems and their

application and performance. In the past, problem areas have covered plumbing,

masonry, roofing, corrosion, mechanical systems, insulation materials, and

underground piping. The benefits of this research, however, extend far beyond

its military application, to other government agencies and into the private sector.

148 


\section{AASHTO MATERIALS REFERENCE LABORATORY (AMRL)}

James H. Pielert

(301) 912-3481

Building Materials Division

Sponsor: American Association of State Highways and Transportation Officials

Under this project, with the support of AASHTO Research Associates working under CBT supervision, measurement services are provided to both public and private laboratories working on transportation studies. At present, attention is focused on the testing of soils and bituminous materials and the measurement of frictional properties of highway. Procedures used in performing conventional quality assurance tests are observed for conformance with applicable national standards. Related test apparatus is checked with inspection equipment traceable to CBT-calibrated devices. Deficiencies noted during inspections are brought to the attention of laboratory managers. In addition, proficiency-test samples are distributed at regular intervals to obtain information on 1aboratory performance. The primary goal of the AMRL is improvement in the quality of testing in bituminous and soils laboratories. Specific products include a detailed report on each inspection performed; a comprehensive report on each round of proficiency-sample testing; and input to the work of standards committees, such as data for use in standards for testing soils and bituminous materials. 


\section{PERFORMANCE OF ROOFING SYSTEMS}


PROBABILISTIC STUDY OF SINGLE-PLY MEMBRANES

James R. Clifton

(301) 921-3458

Building Materials Division

Sponsor: Nationa1 Bureau of Standards

In developing and demonstrating a probabilistic method for predicting service life of single-ply roofing membranes, membranes will be subjected over time to both mechanical and thermal stresses. Time-to-failure distributions will be obtained for each experimental condition (minimum of three temperature levels and three mechanical stress levels). The degree of functional dependence of the time-to-failure distribution parameters on temperature and mechanical stresses will be determined through time-temperature superposition and timemechanical stress equations. Other experimental variables that will be used include membrane characteristics (seam, no seam), and characteristics of the thermal insulation (gap and no gap between insulation boards, no insulation). Both creep and stress relaxation experiments will be performed. EPDM (ethylene propylene diene monomer) will be used as the first-test membrane material, representing the rubber-like single-ply membrane family. Other membrane materials which may be used in future studies are modified bitumens and thermoplastics, and other rubber-1ike materials.

Information on the service life of membranes will help minimize premature failures of the $\$ 3$ billion or more of single-ply membranes that are estimated to be put in place every year. Also, this project will serve to demonstrate to the roofing community the benefits of the probabilistic method in predicting the service lives of roofing materials. 
In the second part of FY85, research will be carried out to develop a method to measure the pore size and pore-size distribution of coatings. These are particularly important characteristics in understanding the rate-controlling processes of degradation. The method will collect data essential for advancing the predictive modeling phase of coatings research. 


\section{PERFORMANCE CRITERIA FOR BITUMINOUS MEMBRANE ROOFING}

Wa1ter Rossiter

(301) 921-3109

Building Materials Division

Sponsor: E.I. duPont de Nemours \& Company

CBT developed preliminary performance criteria in the late $1970^{\prime}$ s for the selection of conventional 4-ply built-up bituminous membranes composed of organic or glass felts and hot bitumen (asphalt and coal tar pitch). The performance criteria were empirically determined based on field performance and laboratory data. In recent years membranes containing reinforcing fabrics (e.g. polyester) with properties considerably different from those of conventional reinforcing felts have been introduced. Currently about 2 billion square feet of bituminous membrane roofing are applied annually in the United States at a cost of over 6 billion dollars.

The objectives of this study are to reassess performance criteria for bituminous membrane roofing and to revise preliminary performance criteria in those cases where a technical basis exists for revision. The first phase of the study will be to augment the technical basis to be used in reviewing earlier preliminary performance criteria. In the second phase of the study, criteria will be revised for those attributes selected in the first phase. The revisions will take into account the results of tests on laboratory-prepared and field specimens. 


\section{QUALITY ASSURANCE OF ROOF SYSTEMS}

Walter Rossiter

(301) 921-3109

Building Materials Division

Sponsor: U.S. Postal Service

The objective of this project is to provide the technical basis for the Postal Service to improve quality assurance in the design, construction, and maintenance of low-sloped roofing, and select cost-effective and durable materials and systems for use in new, replacement, and repair roofing applications. The total roof area of the buildings used by USPS is estimated to be more than 200 million square feet. The majority of these buildings have low-sloped roofing systems. A conservative estimate of USPS annual roofing costs is over $\$ 50$ million for repair, replacement, and new construction. This project consists of a planning effort to include discussions with key USPS personnel to obtain an understanding of USPS roofing practices and types of roofs. This is followed by roofing problem identification, design of roofing systems, materials selection, roofing systems installation and application practices, and maintenance practices.

The project's product will be a report describing the results of the study and recommendations for improving the quality assurance of USPS roofing and recommendations for further research. The findings will assist USPS reduce premature roofing failures through improved material selection and maintenance practice. It also will provide information on the types of roofing material failures experienced in service which will be valuable in planning the future course of roofing research at $\mathrm{CBT}$. 


\section{PREDICTING}

THE PERFORMANCE

AND SERVICE-LIFE

OF CONCRETES 


\section{IDENTIFYING THE DEGRADATION MECHANISMS OF CONCRETE}

Larry Knab

(301) 921-3120

Building Materials Division

Sponsor: National Bureau of Standards

Improved recognition and understanding of degradation mechanisms in concrete and the effects of the environment on these mechanisms is needed to assess degradaton in concrete, and to develop improved models to predict the service life of new concrete or the remaining service life of existing concrete. The purpose of this project is to develop a technical basis for improved prediction of concrete performance including improvements in methods of characterizing degradation, understanding of degradation mechanisms, and tools (e.g., mathematical models, expert systems) for predicting concrete service life.

In FY84, the microstructural details of the fracture zone in mortar subjected to cyclic loading were compared with those for mortar subjected to monotonically increasing load using the fluorescent thin-section method developed in FY83. Data indicated little, if any, microcracking at the one micrometer level and above with either cyclic or monotonic loading. It appears that crack tortuosity and/or aggregate bridging (interlock of aggregate with matrix) provide traction across the crack walls behind the crack tip for the loading types studied. In addition to providing information on the microstructural details of the fracture zone, fluorescent thin sections should be useful in elucidating other cracking processes, whether resulting from chemical reactions, corrosion of reinforcement, freeze-thaw action, or high-temperature curing. 
In FY85, improved methods of characterizing the microstructure of concrete and mortar are being investigated. Emphasis is on the recognition and enhancement of the microstructure as related to degradation mechanisms. Advanced methods for characterizing both fine microstructure (less than one micrometer) and coarse microstructure (greater than one micrometer) of sound and deteriorated concretes will be demonstrated.

The quality of the concrete used to rebuild America's infrastructure will be improved as a result of this study. Improved methods for characterizing degradation will be used to provide the basis for: (1) condition assessment of existing concrete structures, including those needing repair or rehabilitation, and (2) developing models and expert systems to predict the service life of new concrete or the remaining life of existing concrete. 


\section{MEASUREMENT OF THE STRENGTH OF THE BOND BETWEEN OLD AND NEW CONCRETE}

Leslie Struble

(301) 921-2635

Building Materials Division

Sponsor: Tri-Services Committee

Good bond between old and new concrete is essential to the repair of concrete structures. Available methods to achieve a strong bond generally involve both preparation of the old concrete surface and use of materials with epoxy resin or other polymers incorporated in the fresh concrete. To evaluate the repair materials, the tensile strength of the bond between the new material and the old concrete should be measured directly, but at present there is no commonly accepted test. The development of such a test is the objective of this project.

The principal features of the test method will include: preparation of samples with a single planar interface between the constituents, tensile loading normal to this interface using grips that minimize shear or torque, and testing the bond between new and old cement paste, rather than concrete, because paste is considered the critical constituent for bond strength. Samples will be prepared by casting fresh cement paste or related repair material against a smoothed surface of old hardened paste.

Test development will be based on a method used in an earlier study of the bond between cement paste and aggregate, though modification of the grips will probably be required. The grips used earlier exert considerable compressive force on each end of the specimen, and the paste may not be sufficiently strong to withstand this force. 
Once the test has been modified and shown to be effective, it can be used in future years to determine what parameters in the fresh paste or repair material affect the tensile strength of the bond between fresh paste and old paste, and to provide selection criteria for repair materials. This research will benefit concrete technology, especially the repair of concrete structures. It also will provide the Department of Defense with improved criteria for selecting of materials for repair. In addition, it will add to our fundamental understanding of bonding in concrete, a phenomenon important in many aspects of concrete science. 
PERFORMANCE REQUIREMENTS, TESTS, AND CRITERIA FOR MATERIALS USED TO REPAIR PORTLAND CEMENT CONCRETE

Larry Knab

(301) 921-3120

Building Materials Division

Sponsor: U.S. Army Corps of Engineers through Waterways Experiment Station

An important part of the U.S. Army, Corps of Engineers' REMR program is the repair of concrete. A large number of materials are currently available for repairing concrete. Often, however, their performance has been unsatisfactory. The lack of success with these materials has been attributed, at least in part, to an inadequate technical basis for their selection. The purpose of this research is to determine preliminary performance criteria for selecting materials to repair concrete structures which have cracks, spalls, or scaling. The determination of performance criteria for materials selection should improve the field performance of materials used in concrete repair.

Existing knowledge on performance requirements, tests, and criteria for materials used to repair portland cement concrete will be analyzed. Published information on the relationship between performance requirements and performance in service will be studied. Based on this information, the performnce requirements (e.g., resist shear forces) and associated material properties (e.g., shear strength) for the important in-service degradation factors, such as mechanical stress, temperature and temperature fluctuations, moisture, aggressive chemicals, ultraviolet light, and time of exposure will be identified. A rationale for determining performance tests and criteria based on existing knowledge will be developed. Performance tests and criteria will then be determined for appropriate performance requirement - degradation factor combinations, based on existing knowledge. Needs for new performance 
tests and criteria will be identified and developed. The project will be performed in three phases. Performance requirements, tests, and criteria will be determined for materials used to repair cracks (Phase I), spalls (Phase II), and scaling (Phase III) in concrete. Based on assessment of existing performance criteria, a research plan for developing needed performance tests and criteria will be developed. 


\section{ALKALI-SILICA REACTION IN CONCRETE}

\section{Leslie Struble}

(301) 921-2635

Building Materials Division

\section{Sponsor: National Science Foundation}

The objective of this research is to explore whether the alkali mineralogy of cement affects the mortar expansion due to alkali-silica reaction. Alkalisilica reaction is a major concern in the production of durable concrete. Reaction between alkalies from the cement and reactive silica in the aggregate may cause expansion, cracking, and occasionally significant weakening of the structure. The mechanisms involved in this reaction are not well understood, and this research was undertaken to improve our understanding.

The experimental approach consists of determining the distribution of alkalies within a group of commercial portland cements with a variety of alkali mineralogies, and measuring expansion of mortar bars prepared using these cements and various reactive and unreactive aggregates. 


\section{CEMENT AND CONCRETE REFERENCE LABORATORY (CCRL)}

James H. Pielert

(301) 921-3481

Building Equipment Division

Sponsor: American Society for Testing and Materials, U.S. Army Corps of Engineers

Over $\$ 4$ billion of hydraulic cements are produced in the United States each year. The value of the concrete construction in which these cements are used is estimated to be on the order of $\$ 20$ billion. Because of the large amounts of money and critical construction materials involved, standardization of testing to enhance the reliability of quality-assurance measurements is most important. The CCRL contributes to this standardization through on-site inspections of apparatus and procedures used in the testing of cements and concretes, the distribution of proficiency test samples, laboratory investigations of testing problems, and participation in the activities of standards development groups. This work is performed by ASTM Research Associates working under CBT supervision.

Services under the project include the on-site inspection of the laboratory and the distribution of proficiency test samples. Procedures used in performing conventional quality assurance tests are observed for conformance with applicable national standards. Related test apparatus is checked with inspection equipment calibrated by NBS personnel. Proficiency test samples of portland cement, concrete, blended cement, and masonry cement are distributed at regular intervals to obtain information on laboratory performance. Participation in the work of ASTM technical committees by CCRL staff is a mechanism used to provide the standards community with information developed by the inspection and proficiency sample programs. 


\section{CEMENT HYDRATION COMPETENCE PROJECT}

Paul W. Brown

(301) 921-3458

Building Materials Division

Sponsor: National Bureau of Standards

The objective of this project is to improve understanding of the physics and chemistry of cement hydration and the development of microstructure in pastes of portland and related cements; also, to demonstrate the understanding through development and validation of mathematical models based on probable physical and chemical mechanisms. This research will develop a fundamental understanding of reactions of portland and related silicate cements with water and develop mathematical models for predicting the courses of the reactions under various conditions. The work began with studies of the hydration of various preparations of the most important solid phase in portland cements, tricalcium silicate, and have since been extended to other cement phases and mixtures of phases. The work consists of simultaneous development of fundamental mathematical models based on alternative conceptual models. The mathematical models are tested experimentally and revised as needed. Tricalcium silcates and other cement phases used as starting materials are obtained from the few available sources or when necessary manufactured in the laboratory. They are characterized in such terms as chemical composition, particle size and shape distribution, specific surface area, crystallite size, crystal defects, and grain boundary compositions. The materials are reacted with water and solutions of ionic and non-ionic compounds to determine the effects of temperature, and water-solid and water-surface area ratios on the mechanisms and kinetics of 
the reactions. Techniques used are electrokinetic phenomena, heat evolution, volume change, electrical conductivity, x-ray diffraction, differential scanning calorimetry, surface area measurements by gas adsorption, image analysis, and chemical analysis of the aqueous phase. The image analyses are based on results obtained with the scanning electron microscope and the new STEM. This work is carried out in consultation with scientists at the Center for Materials Sciences and the Center for Applied Mathematics. Studies of tricalcium silicate hydration were concentrated in the first two years of the project, and studies of tricalcium aluminate and mixtures of cement phases began in the third year. In the fourth year, investigations on tetracalcium aluminoferrite were carried out. A complementary activity carried out in the project is participation in the committee on mathematical modeling of cement hydration in RILEM (The International Union of Testing and Research Laboratories for Materials and Structures. 


U.S. DEPARTMENT OF COMMERCE

National Bureau of Standards

National Engineering Laboratory

Center for Building Technology 